\title{
Role of Thalamic and Cortical Neurons in Augmenting Responses and Self-Sustained Activity: Dual Intracellular Recordings In Vivo
}

\author{
Mircea Steriade, Igor Timofeev, François Grenier, and Niklaus Dürmüller \\ Laboratoire de Neurophysiologie, Faculté de Médecine, Université Laval, Québec, Canada G1K 7P4
}

Progressively increasing (augmenting) responses are elicited in thalamocortical systems by repetitive stimuli at $\sim 10 \mathrm{~Hz}$. Repeated pulse trains at this frequency lead to a form of shortterm plasticity consisting of a persistent increase in depolarizing synaptic responses as well as a prolonged decrease in inhibitory responses. In this study, we have investigated the role of thalamocortical (TC) and neocortical neurons in the initiation of thalamically and cortically evoked augmenting responses. Dual intracellular recordings in anesthetized cats show that thalamically evoked augmenting responses of neocortical neurons stem from a secondary depolarization (mean onset latency of $11 \mathrm{msec}$ ) that develops in association with a diminution of the early EPSP. Two nonexclusive mechanisms may underlie the increased secondary depolarization during augmentation: the rebound spike bursts initiated in simultaneously recorded TC cells, which precede by $\sim 3 \mathrm{msec}$ the onset of augmenting responses in cortical neurons; and low-threshold responses, uncovered by hyperpolarization in cortical neurons, which may follow EPSPs triggered by TC volleys. Thalamic stimulation proved to be more efficient than cortical stimulation at producing augmenting responses. Stronger augmenting responses in neocortical neurons were found in deeply located $(<0.8 \mathrm{~mm}$, layers V-VI) regular-spiking and fast rhythmic-bursting neurons than in superficial neurons. Although cortical augmenting responses are preceded by rebound spike bursts in TC cells, the duration of the self-sustained postaugmenting oscillatory activity in cortical neurons exceeds that observed in TC neurons. These results emphasize the role of interconnected TC and cortical neurons in the production of augmenting responses leading to short-term plasticity processes.

Key words: augmenting responses; thalamus; neocortex; plasticity; dual intracellular recordings; EPSP
Repetitive stimulation of the thalamus within the frequency range of sleep spindles (mainly $\sim 10 \mathrm{~Hz}$ ) elicits cortical field potentials with progressively growing amplitudes, termed augmenting responses (Morison and Dempsey, 1943). Following the description of cortically generated augmenting (or incremental) responses evoked by white matter or callosal stimulation in thalamically lesioned animals (Morin and Steriade, 1981; Ferster and Lindström, 1985; Nuñez et al., 1993; Steriade et al., 1993b), the cortical mechanisms of such responses have been investigated in experiments on rat motor cortex (Castro-Alamancos and Connors, 1996a,b). The latter studies have emphasized the intrinsic properties and synaptic interconnections of layer $\mathrm{V}$ pyramidal cells in the initiation of cortical augmenting responses.

The thalamus itself can generate augmentation, as shown by both low-threshold (LT) and high-threshold (HT) incremental responses elicited by local thalamic stimulation in thalamocortical (TC) cells of decorticated animals (Steriade and Timofeev, 1997). In that study, we demonstrated that augmenting responses produce a form of short-term plasticity that consists of a progressive and persistent increase in depolarizing synaptic responses of TC cells, as well as a persistent and prolonged decrease in their IPSPs. We proposed that the hyperpolarization-dependent LT augmenting responses of TC cells are mainly attributable to the incremental responses of GABAergic thalamic reticular (RE)

\footnotetext{
Received Feb. 18, 1998; revised May, 7, 1998; accepted May 8, 1998.

This work was supported by Medical Research Council of Canada Grant MT-3689 and Human Frontier Science Program Grant RG-81/96. I.T. (partially supported by the Savoy Foundation) and N.D. are postdoctoral fellows. F.G. is a graduate PhD student, partially supported by Fonds pour la formation des chercheurs et l'aide à la recherche. We thank P. Giguère and D. Drolet for technical assistance.

Correspondence should be addressed to Prof. M. Steriade at the above address. Copyright (C) 1998 Society for Neuroscience $0270-6474 / 98 / 186425-19 \$ 05.00 / 0$
}

neurons, whereas the depolarization-dependent (HT) augmenting responses of TC neurons result from decremental responses of RE neurons in association with incoming excitatory drives (Timofeev and Steriade, 1998). Network models corroborated this mechanism for eliciting incremental responses within interacting TC and RE cells, as well as the generation of augmenting responses in the isolated RE nucleus (Bazhenov et al., 1998a). The intrathalamic generation of augmenting responses is not surprising, because these rhythmic potentials were initially investigated as an analog of spontaneously occurring spindles (Morison and Dempsey, 1943); spindles are also generated within the thalamus in the absence of the cerebral cortex (Morison and Bassett, 1945) as well as in the isolated rostral pole of the RE nucleus deafferented from the remaining thalamus (Steriade et al., 1987).

Despite the demonstration that augmenting responses can be generated within the thalamus, it was emphasized (Steriade and Timofeev, 1997) that the thalamus and the cerebral cortex can each generate such responses and that both of these structures are necessary to produce fully developed augmentation that may eventually lead to self-sustained paroxysmal activity in reciprocal corticothalamocortical loops. This view was the impetus for the present study. Our aim was to compare, by means of dual intracellular recordings from cortical and thalamic neurons in vivo, the behavior of simultaneously impaled neurons in response to thalamic and cortical pulse trains at $10 \mathrm{~Hz}$ and to investigate the temporal relations between the distinguishing features of augmenting responses in these two cellular classes. The data show that thalamic stimulation is more efficient than cortical stimulation in producing augmenting responses in cortex and that, with thalamic stimulation, the incremental responses of neocortical 
neurons largely depend on the postinhibitory rebound spike bursts characterizing the LT-type responses in TC cells. However, the duration of the self-sustained postaugmenting oscillatory activity in cortical neurons exceeds that observed in TC neurons. These results emphasize the role of interconnected TC and cortical neurons in the production of augmenting responses, which lead to short-term plasticity processes. In a companion paper (Bazhenov et al., 1998b) computer simulations of thalamocortical augmenting responses are used to explore the underlying mechanisms.

\section{MATERIALS AND METHODS}

Experiments were conducted on adult cats of either sex $(n=39)$, some anesthetized with pentobarbital (35 $\mathrm{mg} / \mathrm{kg}$, i.p.), others maintained under ketamine-xylazine anesthesia $(10-15 \mathrm{mg} / \mathrm{kg}$ and $2-3 \mathrm{mg} / \mathrm{kg}$, i.m.). Similar results on augmenting responses were obtained under both types of anesthesia (each figure legend mentions the experimental condition). In addition, tissues to be excised and pressure points were infiltrated with a local anesthetic (lidocaine, $2 \%$ ). The depth of general anesthesia was continuously monitored by recording sleep-like EEG patterns (spindle and slow oscillations). Additional doses of anesthetics were administered at the slightest tendency toward lower-amplitude, faster-frequency EEG waves. The heart rate was monitored by means of electrocardiogram and kept constant ( $90-110$ beats $/ \mathrm{min})$. Body temperature was maintained at $37-39^{\circ} \mathrm{C}$. Once the EEG indicated that anesthesia induced sleep-like patterns, the animals were paralyzed with gallamine triethiodide and artificially ventilated by maintaining the end-tidal $\mathrm{CO}_{2}$ concentration at $3.5-3.8 \%$. The stability of intracellular recordings was ensured by cisternal drainage, hip suspension, bilateral pneumothorax, and covering the whole hemisphere with a warm solution of agar (4\% in 1\% saline).

Stimulation and recordings. Repetitive stimuli (trains of five pulses at 10 $\mathrm{Hz}$ ), with variable intensities $(0.02-0.3 \mathrm{~mA})$ and durations $(0.05-0.2$ $\mathrm{msec}$ ), were delivered through stereotaxically inserted coaxial electrodes into relay [ventrolateral (VL)], association [lateroposterior (LP)], and rostral intralaminar [centrolateral (CL)] thalamic nuclei, as well as in precruciate (areas 4 and 6) and suprasylvian (areas 5 and 7) cortices, depending on the sites of recordings. Intracellular recordings were performed in conjunction with recording of field potentials from neocortical motor and association areas 4, 6, 5, 7, and 21. In the thalamus, we recorded intracellularly from VL and RE nuclei. For intracellular recordings and staining, we used glass micropipettes filled with a solution of 2.5-3 M potassium acetate and $2 \%$ neurobiotin (DC resistance, $30-50$ $\mathrm{M} \Omega$ ). A high-impedance amplifier with active bridge circuitry was used to record the membrane potential $\left(\mathrm{V}_{\mathrm{m}}\right)$ and inject current into the cells. Intracellular activities were recorded, together with field potentials, on an eight-channel tape with a bandpass of $0-9 \mathrm{kHz}$, digitized at $20 \mathrm{kHz}$ for off-line computer analysis.

Histology. At the end of experiments, the animals were given an intravenous lethal dose of pentobarbital and perfused intracardially with physiological saline, followed by $4 \%$ paraformaldehyde and $1 \%$ glutaraldehyde. The brain was removed, stored in formalin with $30 \%$ sucrose, and finally sectioned at $80 \mu \mathrm{m}$, processed with the avidin-biotin standard kit, mounted on gel-dipped slides, and coverslipped. Reconstructions of different types of cortical neurons (see Fig. 12) were performed from series of adjacent sections. The difference between the depth of cortical cells estimated by intracellular staining and by micromanipulator readings was $<15 \%$ (Steriade et al., 1993a; Contreras and Steriade, 1995).

\section{RESULTS}

We present the results in the following order. First, intracellular recordings from single cortical neurons show the selectivity of augmenting responses in different cortical areas, evoked by stimulation of the appropriate dorsal thalamic nucleus, the secondary depolarizing component that selectively develops during augmentation, and the dependency of augmenting response amplitude on the immediate history of the neuronal network. Next, results from dual intracellular recordings from thalamus and cortex demonstrate that the secondary depolarizing component, which characterizes augmenting responses in neocortical neurons, is preceded by postinhibitory rebound bursts in the simul- taneously impaled TC cell. Finally, dual intracellular recordings and staining of cortical neurons reveal the shorter latencies and higher propensity to thalamically evoked augmenting in deeply lying, compared with more superficial, regular-spiking and fast rhythmic-bursting cells.

\section{Database and neuronal identification}

The following results are based on intracellular recordings of 320 cortical neurons from motor pericruciate areas 4 and 6 and association suprasylvian areas 5, 7, and 21, from 189 thalamic neurons from VL nucleus, and from 9 RE cells. Neurons retained for analysis were recorded for at least $20 \mathrm{~min}$ (but up to $2 \mathrm{hr}$ ). The resting $\mathrm{V}_{\mathrm{m}}$ was more negative than $-60 \mathrm{mV}$ in cortical neurons (mean, $-66 \pm 2.4 \mathrm{mV}$ ) and more negative than $-55 \mathrm{mV}$ in $\mathrm{TC}$ cells (mean, $-60 \pm 1.8 \mathrm{mV}$ ). Action potentials were overshooting. Of those 518 cortical and thalamic neurons, we performed 59 simultaneous recordings from cortical area 4 and thalamic VL or RE neurons and 27 simultaneous recordings from two cortical neurons located in areas 4 and 5 or 7 .

(1) Cortical neurons belonged to different electrophysiologically defined classes: regular-spiking (68\%), intrinsically bursting $(12 \%)$, and fast rhythmic-bursting $(20 \%)$. The former two classes have been described in previous in vitro (Connors et al., 1982; McCormick et al., 1985) and in vivo (Nuñez et al., 1993) studies. The fast rhythmic-bursting cells have been described in superficial layers of visual cortex (Gray and McCormick, 1996) as well as in superficial and deep layers of motor and association areas (Steriade, 1997; Steriade et al., 1998), and they produce depolarization-dependent high-frequency $(400-600 \mathrm{~Hz})$ spike bursts recurring rhythmically at $30-40 \mathrm{~Hz}$. Cortical neurons received short-latency excitation from appropriate thalamic nuclei, and some of them were formally identified as corticothalamic by antidromic invasion (see Figs. 3, 4). (2) All neurons recorded from dorsal thalamic nuclei belonged to the TC class, as demonstrated by powerful LT rebound spike bursts deinactivated by membrane hyperpolarization (Deschênes et al., 1984; Jahnsen and Llinás, 1984) and backfiring from the projection cortical area. (3) RE neurons, recorded from the rostrolateral sector of the RE nucleus, were identified by their depolarizing envelope during spindles and the accelerando-decelerando pattern of their spike bursts (Domich et al., 1986; Steriade et al., 1986).

\section{Buildup of thalamically elicited augmenting responses in cortical neurons}

We first investigated the topographical relation between the stimulated site in the dorsal thalamus and the type of evoked responses in different neocortical areas. Although augmenting responses are localized in cortical territories that are topographically related to the thalamic stimulus, and the field potentials are depth-negative (Morison and Dempsey, 1942; Spencer and Brookhart, 1961), cortical recruiting responses elicited by the thalamic ventromedial (VM) nucleus, which projects widely over the cerebral cortex, are negative at the surface, because the VM nucleus exerts depolarizing actions onto layer I (Glenn et al., 1982). The present study mainly dealt with depthnegative field potentials associated with depolarizing responses in cortical neurons, characteristic of augmenting responses. Occasionally, however, prevalent depth-positive augmentation was observed (see VL-evoked field responses in Fig. 1 and CL-evoked recruiting in area 5, simultaneously with CL-evoked augmenting in area 21; see Fig. 4). In fact, augmenting responses should not be considered as sharply distinct from recruiting ones: both types 

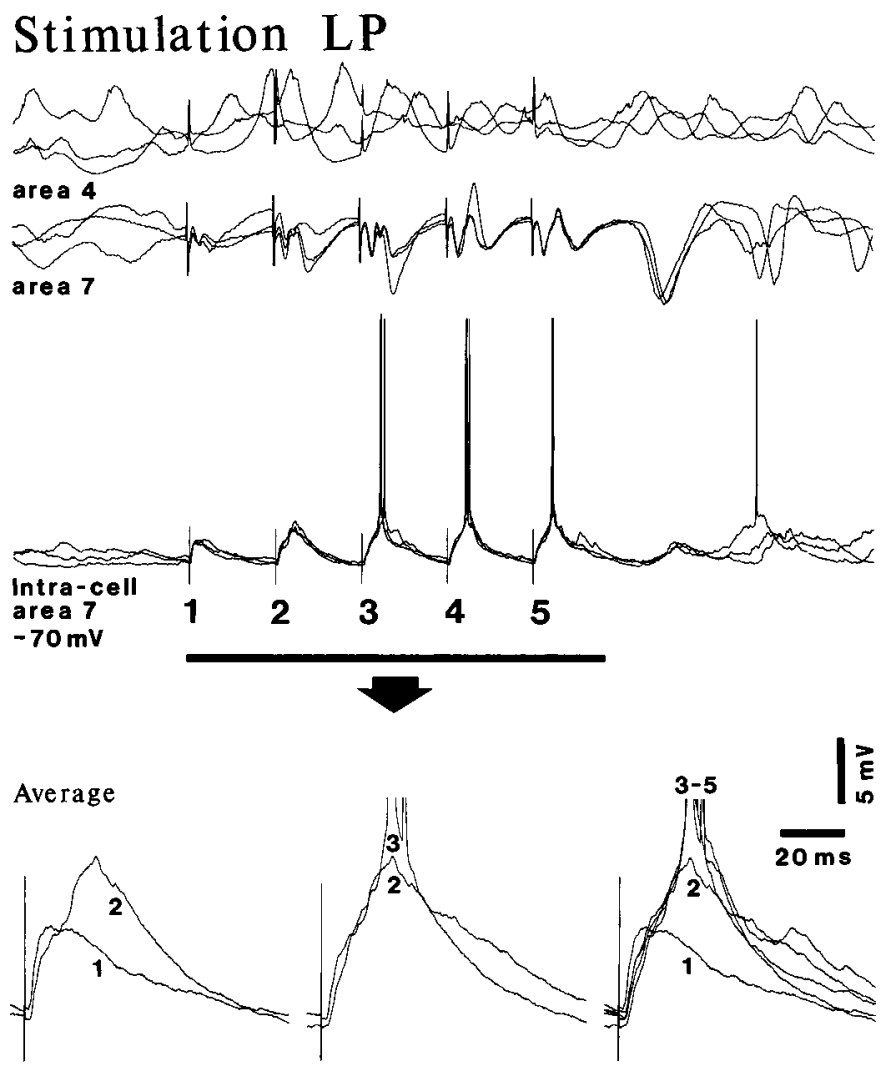

\section{Stimulation VL}
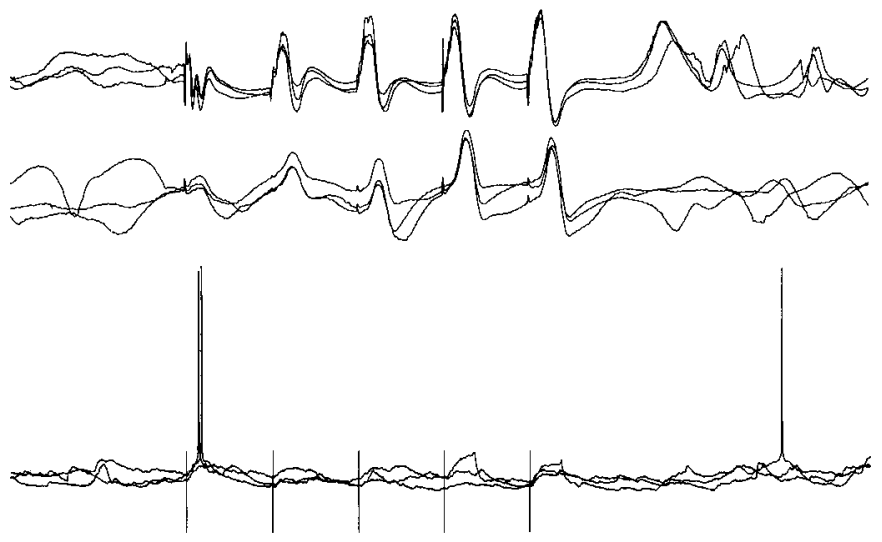

Stimulation area 7

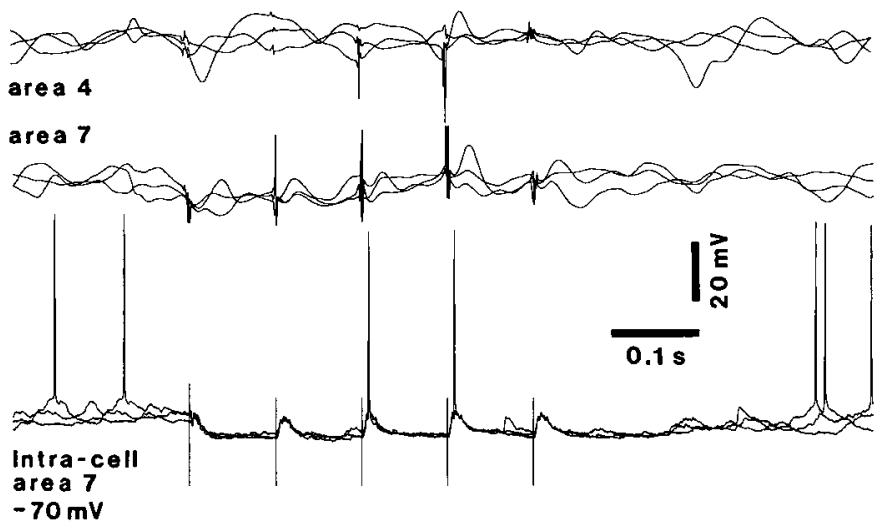

Figure 1. Specificity of augmenting responses in different thalamocortical systems. Barbiturate anesthesia. Three simultaneously recorded sites (each with three superimposed traces) are (from top to bottom) field potentials from depth of area 4 and depth of area 7 and intracellular activity of area 7 neuron. The LP-evoked $(10 \mathrm{~Hz})$ augmenting responses in area 7 neuron are expanded below (arrow). Below, averages $(n=3)$ of responses to different stimuli in the pulse train at $10 \mathrm{~Hz}$ (numbers of responses to LP stimuli correspond to those in the above panel) showing that augmenting already occurred with the second stimulus and selectively developed from a late depolarization whose onset latency was at $\sim 13$ msec. Repetitive LP stimulation induced augmenting responses in both neuron and field potentials recorded from area 7 (and virtually no response in area 4); VL stimulation induced recruiting responses with highest amplitudes in area 4. Stimulation of cortical area 7 evoked negligible augmentation in area 7 cell and field potentials and produced steady hyperpolarization $(\sim 6 \mathrm{mV})$ in area 7 cell. Time and voltage calibration in the bottom right panel is valid for all other panels (with the exception of expanded averages).

depend on the prevalent (although not exclusive) laminar projections of different thalamic nuclei. The VM and some intralaminar nuclei preferentially project to layer I but also have deeper projections, and specific relay nuclei have, in addition to their major projections to middle layers, superficial projections arising from small-sized neurons (Jones, 1985; Steriade et al., 1997).

During spontaneously occurring spindles, intracellularly recorded cortical activities and field potentials from related thalamic nuclei were time-locked (see Fig. 8). Stimulation of various thalamic nuclei, while recording intracellularly from the same cortical neuron, showed that clear-cut augmenting responses were selectively induced by stimulating the thalamic nucleus projecting to the recorded cortical area. Figure 1 shows that LP stimulation elicited intracellular and field potential augmenting responses in suprasylvian area 7 but not in area 4, whereas VL stimulation elicited recruiting responses with highest amplitudes in area 4. Cortical stimulation, even when applied close $(\sim 2 \mathrm{~mm})$ to the intracellularly recorded area 7 neuron, did not elicit augmentation but, rather, a prolonged hyperpolarization.

As shown in Figures 1 and 2, cortical augmenting responses developed from a secondary depolarizing component that ap- peared from the second thalamic stimulus and continued until the last (fifth) stimulus in the $10 \mathrm{~Hz}$ train. This feature was observed in all analyzed cortical neurons $(n=120)$. In a majority of them $(n=92)$, the increased amplitude of the secondary depolarization (initiated at 7-16 msec; mean, $11 \pm 0.8 \mathrm{msec}$ ) was associated with a diminished amplitude of the early depolarization. In Figure 2, the LP-evoked early depolarization in area 7 neuron diminished in amplitude by $65 \%$ at the second stimulus, and the VL-evoked early depolarization in area 6 neuron diminished by $37 \%$. In both neurons, incremental responses grew from the secondary depolarization, from the second (Fig. $2 A$ ) or third response (Fig. $2 B$ ), continuing up to the end of the pulse train.

The study of thalamically evoked augmenting responses in cortical neurons at different membrane potentials $(n=27)$ provided further evidence for the selective development of augmenting responses from a secondary depolarization. The layer $\mathrm{V}$ corticothalamic cell in Figure 3 (identified by backfiring from CL nucleus) displayed a monosynaptic EPSP at $2.5 \mathrm{msec}$, evoked by the first CL stimulus in the pulse train at $10 \mathrm{~Hz}$. The response latency did not change from rest $(-64 \mathrm{mV})$ to a hyperpolarized level $(-72 \mathrm{mV})$. At a depolarized level $(-55 \mathrm{mV})$, the cell also 
A
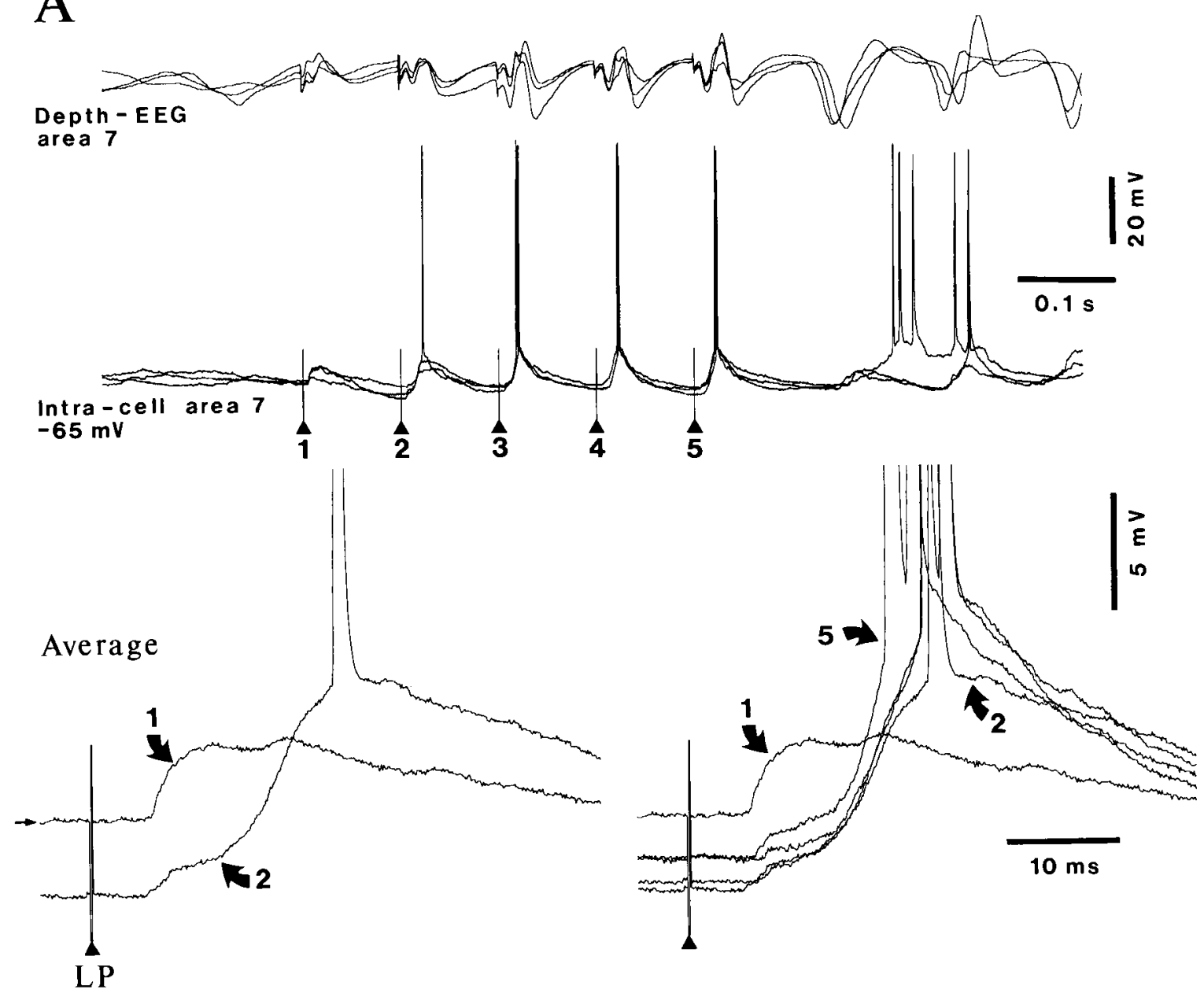

B

Average
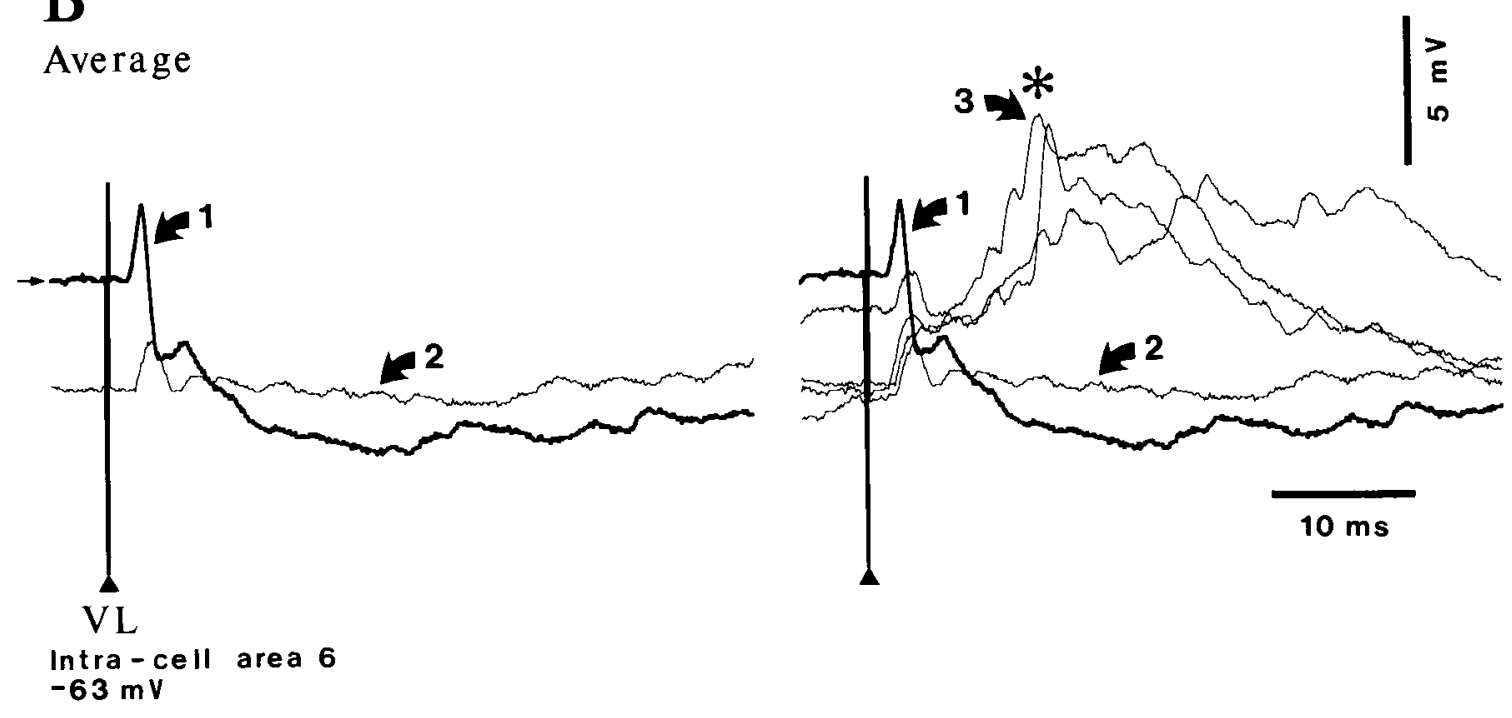

Intra-cell area 6

Figure 2. Cortical augmenting responses to thalamic repetitive stimuli $(10 \mathrm{~Hz})$ develop from a late depolarization. Barbiturate anesthesia. $A$, LP-evoked augmenting responses in field potentials and intracellularly recorded neuron from suprasylvian area 7 . Three superimposed traces. Below, Average $(n=$ 3 ) of cellular responses to the first and second stimuli in the $10 \mathrm{~Hz}$ train (left) and to all five stimuli in the pulse train (right). Note that the amplitude of the early EPSP (latency, $\sim 5 \mathrm{msec}$ ) diminished at the second stimulus and that a secondary depolarization (onset latency, $\sim 12 \mathrm{msec}$ ), leading to action potential, appeared from the second stimulus. $B$, Precruciate area 6 cell, displaying augmentation with $10 \mathrm{~Hz}$ V L stimuli. Average ( $n=3)$ of responses shows that, compared with the response evoked by the first stimulus in the train (thick trace), the amplitude of the early EPSP (latency, 1.7 msec) evoked by the second stimulus diminished (as in $A$ ), and late augmented depolarization (latency, $\sim 7-8 \mathrm{msec}$ ) occurred starting with the third response (asterisk at right). Note multiple EPSPs building up the secondary depolarization. 

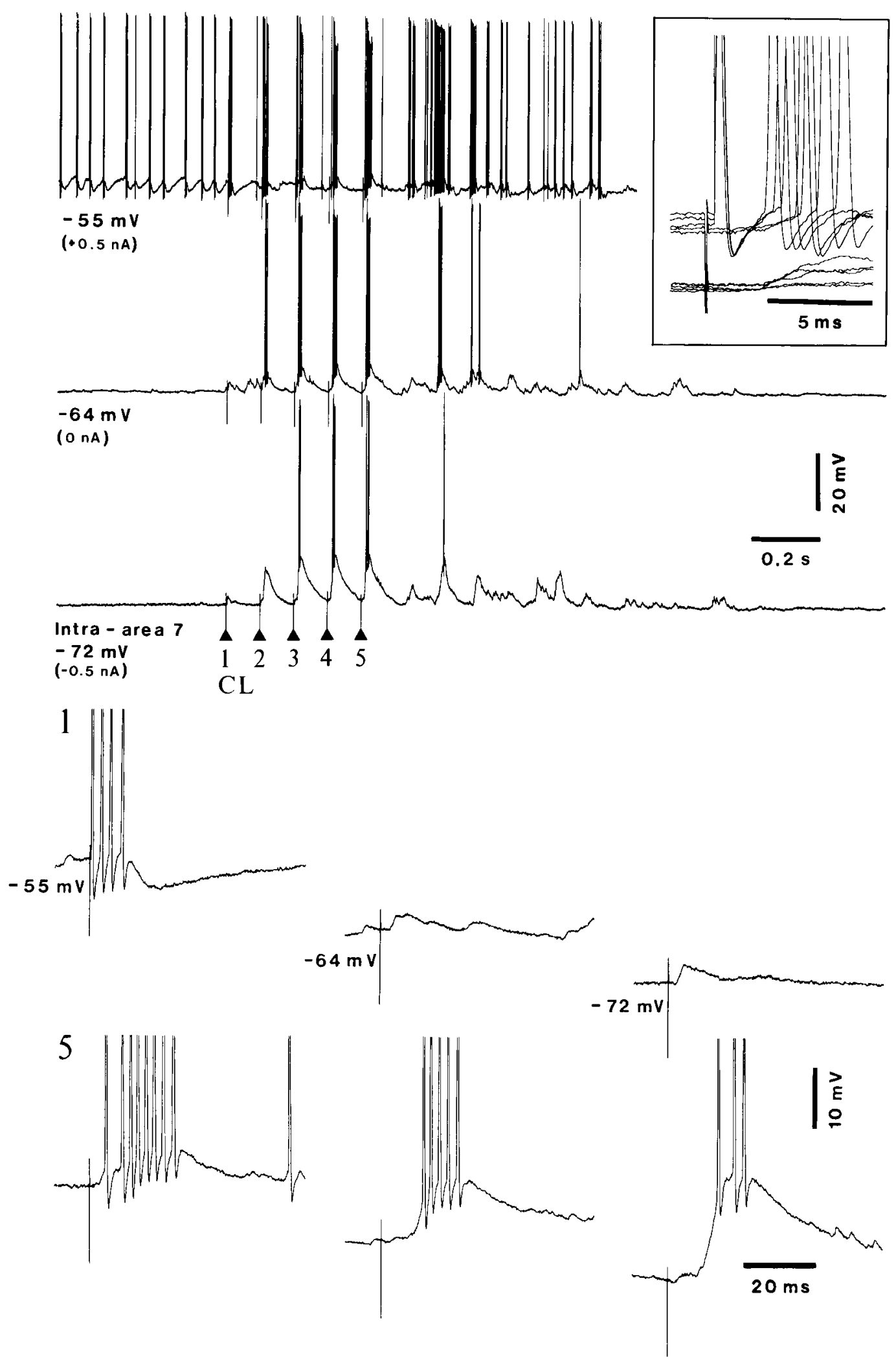

Figure 3. Thalamocortical augmenting responses in area 7 corticothalamic cell at different $\mathrm{V}_{\mathrm{m}}$ levels. Barbiturate anesthesia. Stimulation (10 Hz) of rostral intralaminar CL nucleus. Inset, Neuronal identification by CL stimulus: at $-55 \mathrm{mV}$ (top traces), antidromic spikes (latency, $0.45 \mathrm{msec}$ ) followed by orthodromic responses (latency, $2.5 \mathrm{msec}$ ); at $-64 \mathrm{mV}$ (bottom traces), antidromic spikes failed and synaptic responses survived. Three traces show (left from top to bottom) augmenting responses at a depolarized, resting and hyperpolarized level. The first and fifth responses in the train are expanded below in the same order (from left to right: depolarization, rest, hyperpolarization). Under steady depolarization $(+0.5 \mathrm{nA})$, the augmented response to the fifth stimulus displayed a delayed appearance of the first action potential but a greater number of spikes in the secondary augmented response (compared with that of the 1st response). Also note self-sustained $(1 \mathrm{sec})$ oscillatory response after stimulation, visible at the resting and hyperpolarized levels. 
fired an antidromic spike (latency, $0.45 \mathrm{msec}$ ) in advance of the synaptically driven spike train. By contrast, the augmenting response started at $8.5 \mathrm{msec}$ (simultaneously with a decrease in the early EPSP), at rest as well as at a hyperpolarized level, and consisted of a burst with a frequency of 300-400 Hz.

Augmenting responses were enhanced when preceded by spontaneously occurring spindle oscillations $(n=42)$. In the example depicted in Figure 4, the area 7 corticothalamic neuron was recorded simultaneously with field potentials from the more anterior area 5 and more posterior area 21. Interestingly, the initially depth-negative field augmenting responses in area 21 contrasted with depth-positive (surface-negative) augmenting responses in area 5. This emphasizes that the same thalamic site (in this case the rostral intralaminar CL nucleus) may have different laminar projections to different cortical areas. In the intracellularly recorded area 7 neuron, the CL-evoked depolarizing augmenting responses had a pattern similar to that of spontaneous spindles. When occurring after a spontaneous spindle wave, the augmented responses displayed the same features (including the diminished amplitude of the primary EPSP) but the amplitude of the secondary depolarization increased and led to more action potentials than when the testing CL pulse train was delivered during interspindle lulls (Fig. 4; see Discussion).

Augmenting responses were followed by oscillatory activities within the frequency range of the testing pulse train $(n=215)$. The frequency of self-sustained activity ranged from 8 to 11 $\mathrm{Hz}$ (mean $10 \pm 1.3 \mathrm{~Hz}$ ), and its duration was $\sim 1 \mathrm{sec}$ (see Figs. $3,4,7,8)$.

\section{Development of cortical augmenting responses after the low-threshold rebound bursts in TC neurons}

Dual intracellular recordings were made from cortical area 4 and related VL neurons $(n=32)$. Without exception, the initiation of augmenting responses in area 4 neurons lagged the action potentials of spike bursts crowning the LT-augmented responses in TC cells from the VL nucleus. This relation resulted from analyses using spike-triggered averages, the reference being the first action potential in the augmented thalamic response.

Thalamic stimulation within the VL nucleus induced monosynaptic EPSPs, occasionally preceded by antidromic activation, in TC cells. The excitation was followed by a biphasic IPSP, described in vitro (Hirsch and Burnod, 1987; Crunelli et al., 1988) and in vivo (Paré et al., 1991). During the first, $\mathrm{Cl}^{-}$-dependent IPSP, the fast $(\sim 100 \mathrm{~Hz})$ subthreshold oscillations in VL cells, originating in deep cerebellar nuclei (Timofeev and Steriade, 1997), were obliterated (Fig. 5). The second, 0.1 sec-delayed stimulus in the $10 \mathrm{~Hz}$ pulse train reached the cell during the late part of the IPSP and triggered an LT-type augmented response. The temporal relations between TC and cortical neurons during augmenting responses are illustrated in Figure 5. Similar results were found with both ketamine-xylazine (Fig. 5) and barbiturate anesthesia (data not shown). The responses of thalamic and cortical neurons shared similarities but also exhibited some differences: (1) in Figure 5, spike-triggered averages indicate that, from the second to the fifth augmented responses, the first action potentials in the postinhibitory rebound spike bursts of TC cells (marked by asterisk) preceded by $\sim 3$ msec the onset of augmented secondary depolarizations in cortical neurons; and (2) however, although the number of spikes in the rebound bursts of TC cells progressively increased from the second to the fifth response, the spike trains in the simultaneously recorded cortical neurons did not increase in parallel to TC responses. Thus, in some cases, the maximum number was reached in the third cortical response. The augmented depolarization of the cortical neuron in Figure 5, occasionally superimposed by single spikes, progressively diminished from the onset to the end of incremental responses. In a sample of 27 cortical and thalamic neurons, we determined the evolution of number of spikes, from the first to the fifth response evoked by thalamic repetitive stimuli. The probability of discharge to the first stimulus in the pulse train at $10 \mathrm{~Hz}$ was $p=0.52$ for TC cells and $p=0.31$ for cortical cells. For the second and third responses, the average number of spikes increased by 275 and $438 \%$ in TC cells, and by 238 and $429 \%$ in cortical cells. For the fourth and fifth responses, however, TC cells continued to increase their discharges (546 and 584\% compared with the first stimulus), but cortical neurons reached a saturation level and increased comparatively less or not at all the number of action potentials (477 and $435 \%$ ).

We measured the area (millivolts $\times$ milliseconds) of secondary depolarization in cortical neurons as a function of the number of action potentials in the rebound spike bursts of TC cells during different successive stimuli in pulse trains eliciting augmenting responses $(n=7)$. In Figure 6 , the area of secondary depolarization in area 4 neuron (Fig. $6 b$ ) was stippled to distinguish it from the early (Fig. $6 a$ ) excitatory component elicited by VL stimulation. The averaged augmenting responses to the second and third thalamic stimuli show that the onset of the postinhibitory rebound spike burst in the VL neuron preceded by $\sim 3 \mathrm{msec}$ the onset of the secondary depolarization in the cortical neuron. And the plots indicate a progressive increase in the area of secondary depolarization, parallel to the increased number of action potentials of the VL cell in response to successive stimuli in the pulse train $(r=0.8 ; p=<0.001)$.

\section{Persistent oscillations in cortical neurons after thalamically evoked augmenting responses}

All 320 recorded neocortical neurons displayed activities that outlasted the last stimulus in the $10 \mathrm{~Hz}$ pulse train. The selfsustained rhythmic oscillations, at $\sim 10-12 \mathrm{~Hz}$, were analyzed from both cortical field potentials and intracellularly recorded activities of TC and cortical neurons. (1) Of those 320 neurons, 58 (18\%) displayed only one postaugmenting rebound (Figs. 5, 6; also see Fig. 9, Thalamic stimulation). However, even when there was a single rebound intracellularly, multiple oscillatory cycles occurred in cortical field potentials (Fig. 5), suggesting that other cortical neurons were repetitively depolarized. (2) Of 59 simultaneous recordings from cortical and thalamic VL or RE neurons showing postaugmenting oscillatory activities, the rhythmic selfsustained activity in 16 neurons $(27 \%)$ had a similar duration in the thalamic and coupled cortical cells (see Fig. 8, Evoked). (3) In the majority of cortical neurons, rhythmic waves lasted 0.2-0.6 sec longer than those recorded simultaneously in thalamic cells $(n=32 ; 54 \%)$. The duration of self-sustained cortical activity was longer than thalamic activity (Fig. 7). Even when the selfsustained oscillation was equally long in TC and cortical neurons after thalamically evoked augmenting responses, the oscillations outlasting spindles lasted longer in the cortical cell than in the TC cell (Fig. 8).

\section{Thalamic stimulation is more efficient than cortical stimulation in eliciting augmentation}

The demonstration that the secondary depolarization in cortical neurons follows the rebound spike bursts of TC neurons during augmenting (Fig. 6) suggests that thalamic events are mainly 

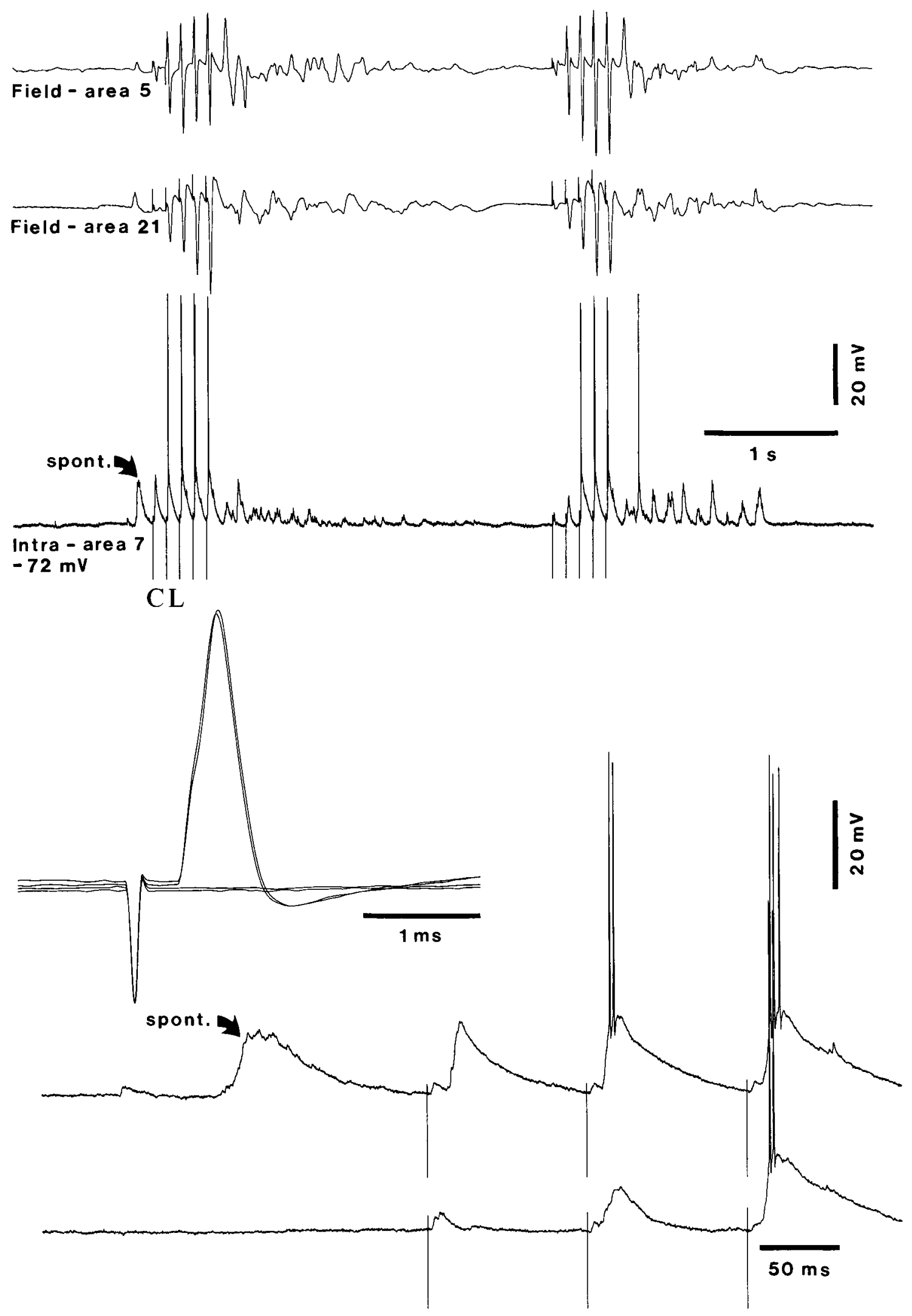

Figure 4. Increased thalamocortical augmenting responses when preceded by spontaneous spindle waves. Barbiturate anesthesia. The three traces depict (from top to bottom) field potentials from the depth of suprasylvian areas 5 and 21 and intracellularly recorded corticothalamic neuron from area 7 (antidromic spikes evoked by threshold CL stimulation are depicted below; latency, $0.4 \mathrm{msec}$; note IS-SD break). Responses to two CL pulse trains at $10 \mathrm{~Hz}$ are illustrated in the top panel: the left one was preceded by the first wave in a spontaneously (spont.) occurring spindle sequence. Augmenting responses to the two pulse trains applied to CL nucleus are expanded below. 


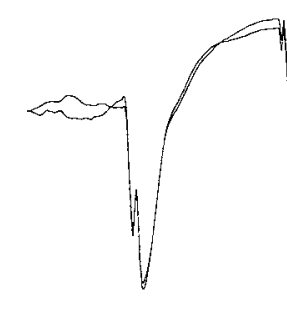

Field - area 4
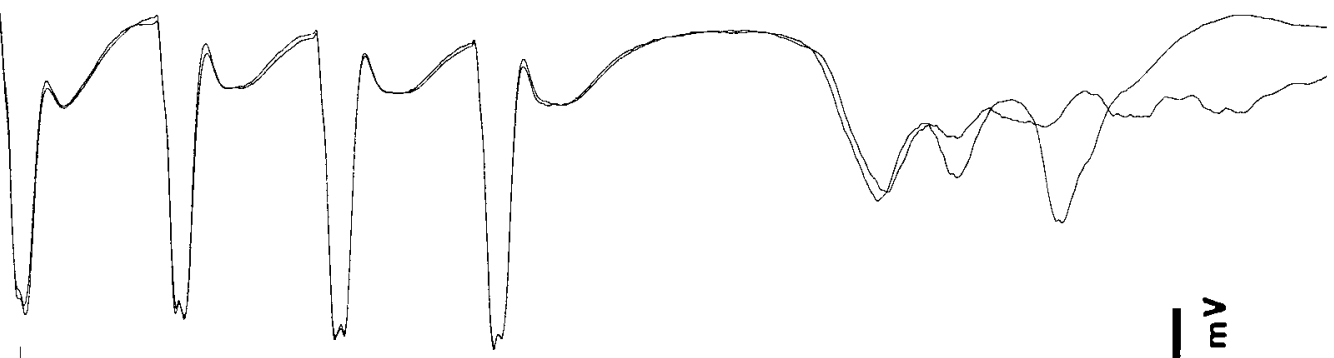

.

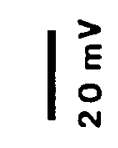

$0.1 \mathrm{~s}$

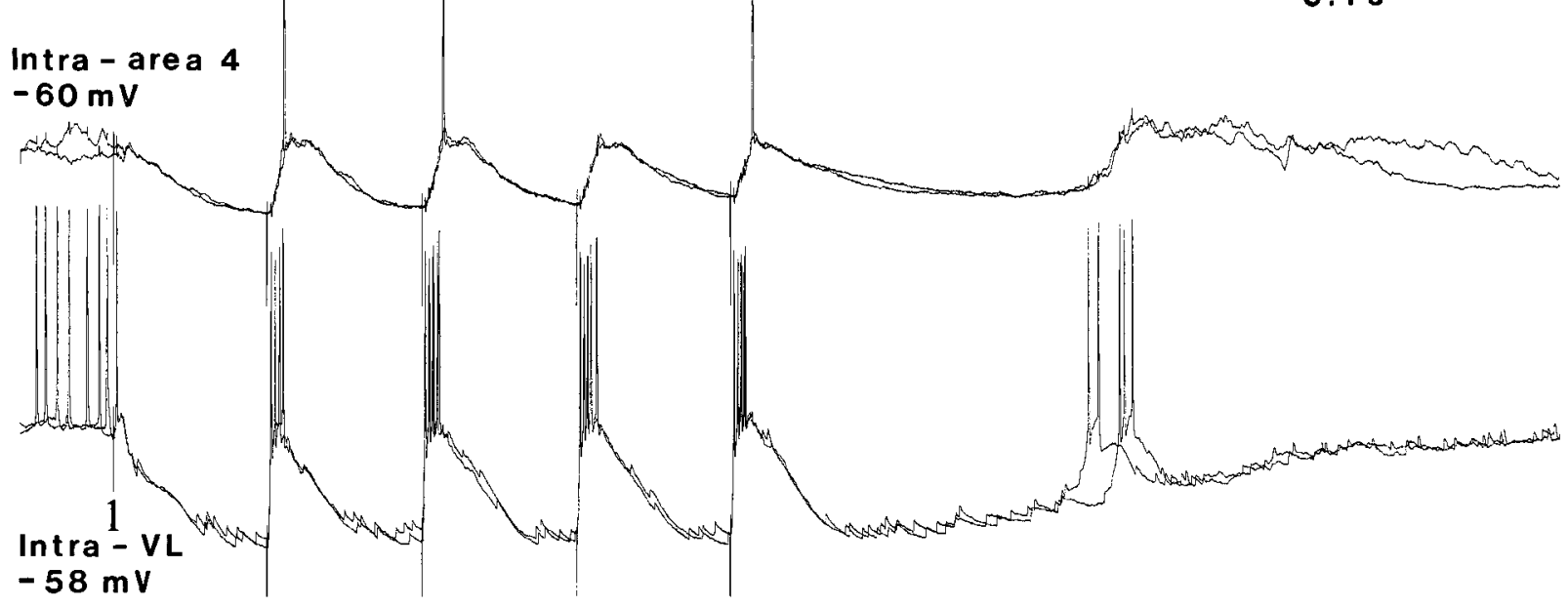

4

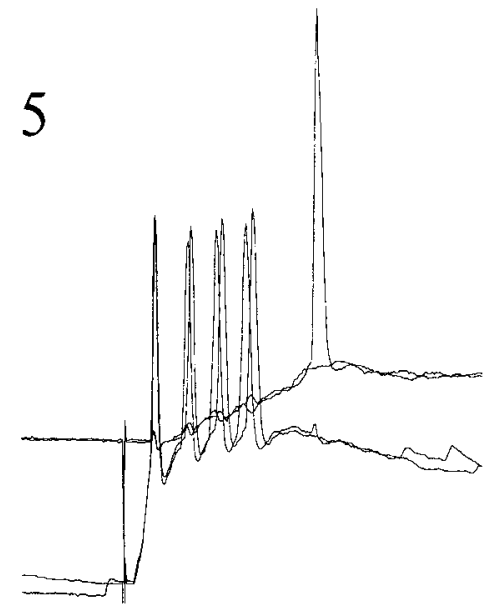

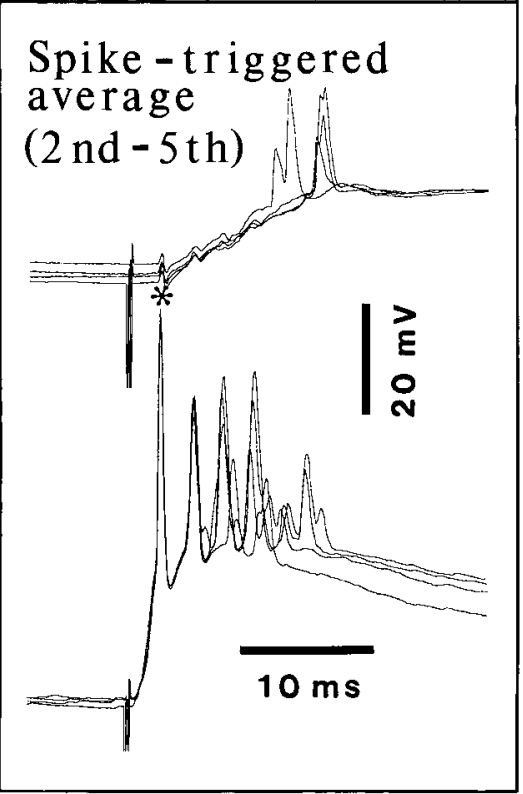

Figure 5. LT augmenting responses in thalamocortical cell precede cortical responses to $10 \mathrm{~Hz}$ thalamic stimuli. Ketamine-xylazine anesthesia. Two superimposed traces in the top panel depict simultaneous recordings of field potentials from area 4 and dual intracellular recordings from area 4 and VL thalamus. Stimuli applied to the VL nucleus. Below, Expanded responses to the first and fifth stimuli in the train. Inset, Average triggered by the first $\mathrm{VL}$ action potential (asterisk) in the second to fifth augmented responses. Small deflections in intracellularly recorded cortical neuron, coincident with action potentials in VL cell (visible in bottom panels), are attributable to capacitive coupling.

responsible for the development of incremental cortical responses. We then supposed that thalamic stimulation will produce more powerful augmenting responses than cortical stimulation, because, in the former case, GABAergic RE neurons are set into action more synchronously. This would induce stronger hyperpolarizations and rebound spike bursts, which are necessary for the LT-type augmenting in TC cells, with direct consequences for cortical augmentation. The comparison between thalamic and 

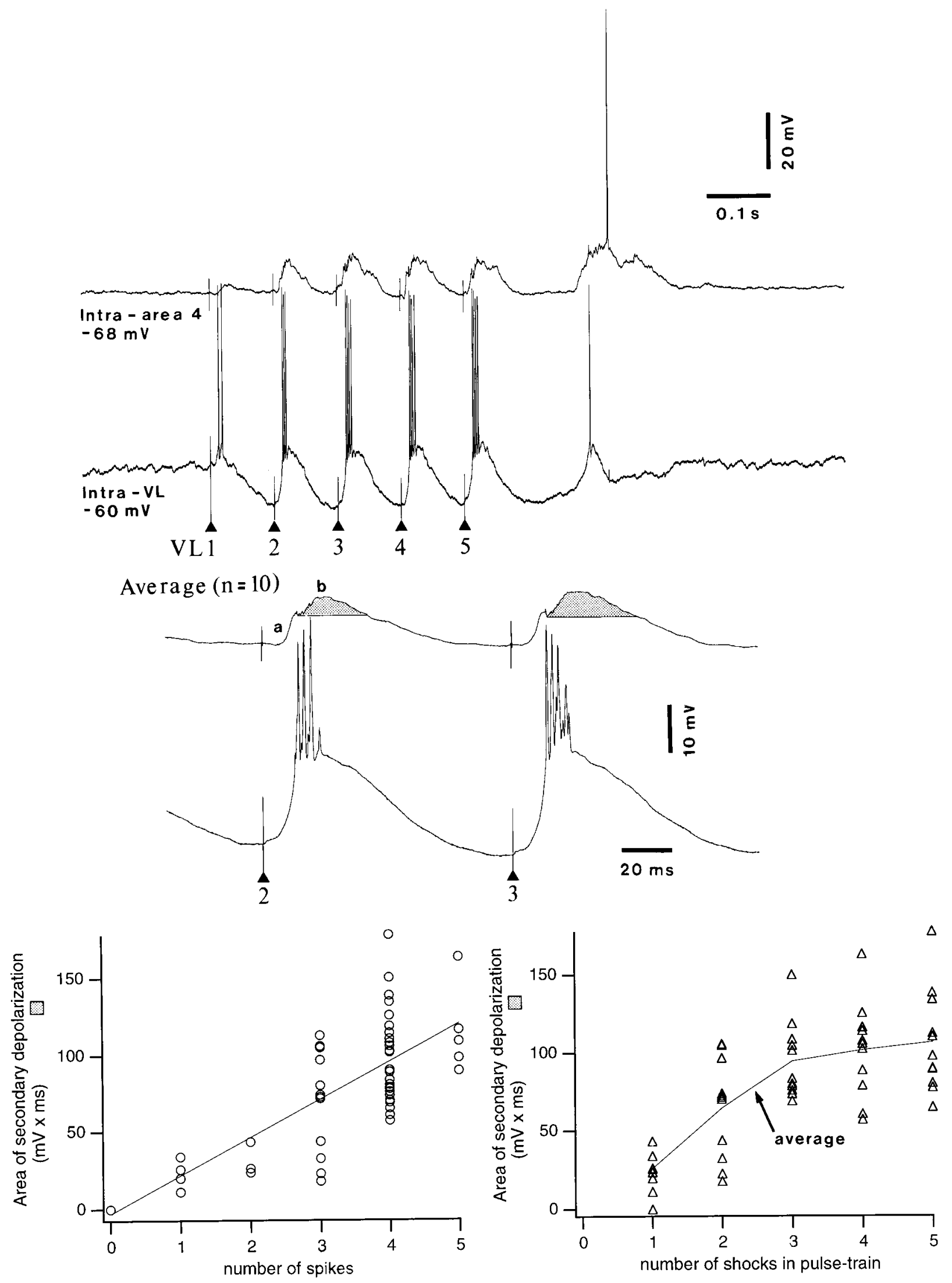

Figure 6. During thalamic-evoked augmenting responses, the depolarization area in cortical neuron increases as a function of number of action potentials in the rebound spike bursts of thalamocortical cell. Ketamine-xylazine anesthesia. Top two traces, Dual intracellular recordings from VL and area 4 neurons. Below, Average of second and third responses in thalamic and cortical cells. The area of secondary depolarization $(b)$ in the response of cortical neuron is marked by dots. Left plot, Area of secondary depolarization of cortical cell as a linear function of number (Figure legend continues) 

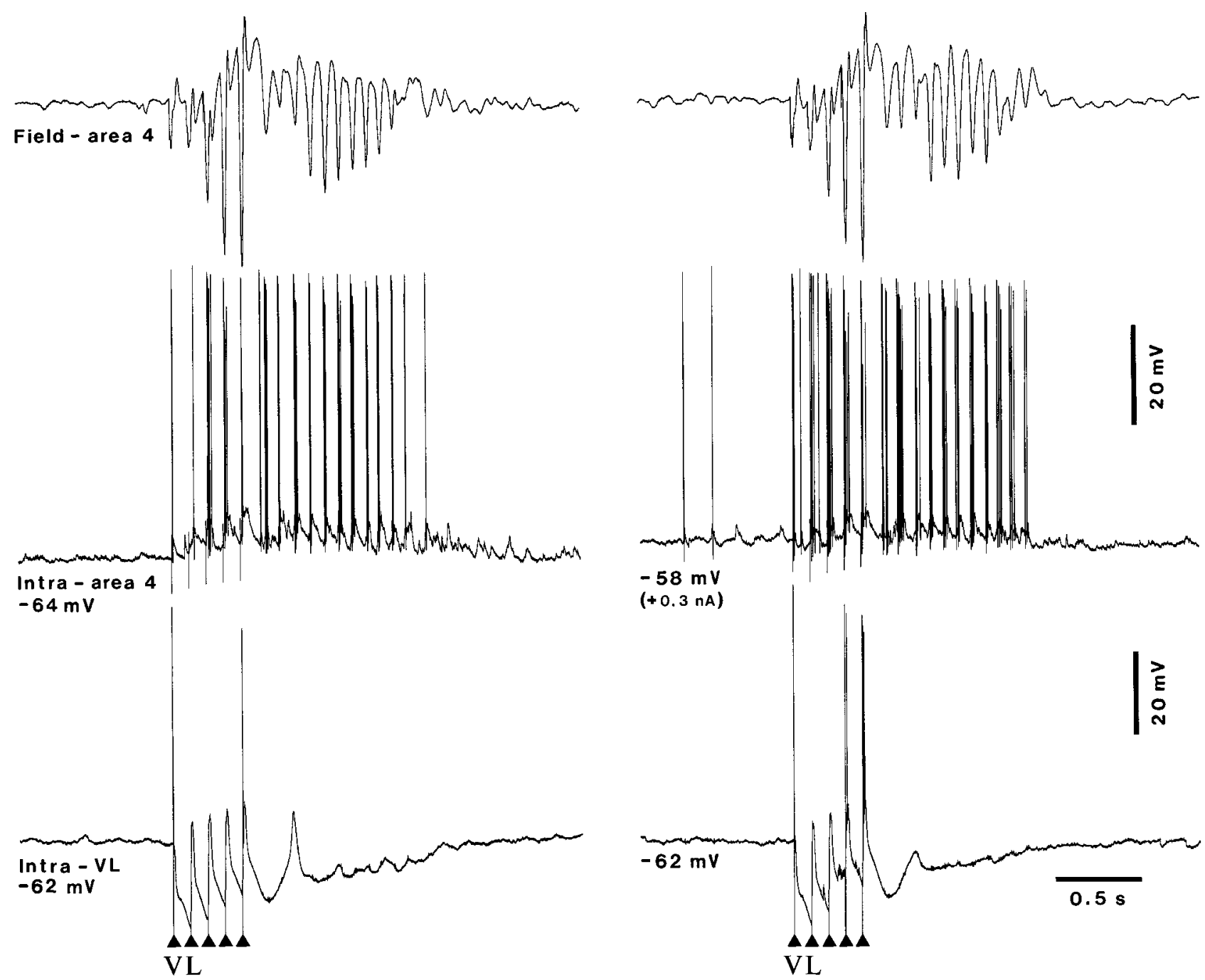

Figure 7. Persistent, self-sustained, postaugmenting oscillation in cortical neuron. Barbiturate anesthesia. Simultaneous intracellular recordings from $\mathrm{VL}$ and area 4 neurons, in conjunction with field potential from the depth of area 4 . Stimulation at $10 \mathrm{~Hz}$ to the $\mathrm{VL}_{\mathrm{L}}$ nucleus. Two $\mathrm{V}_{\mathrm{m}}$ values in cortical neuron (left, $-64 \mathrm{mV}$; right, under $+0.3 \mathrm{nA},-58 \mathrm{mV}$ ). Note persistent, spindle-like oscillation at the same frequency of augmenting responses in area 4 , contrasting with a single clear-cut LT rebound in the VL cell.

cortical rhythmic stimulation was investigated in five cell pairs. In each case, augmentation was much stronger when evoked by thalamic stimuli. Figure 9 shows that, in the same cell pair, thalamic stimulation, close to the VL-recorded neuron (1-2 mm apart), produced LT-type augmenting in the TC cell, with progressively increasing number of action potentials in the rebound bursts, preceding augmentation in the area 4 neuron. In contrast, cortical stimulation close to the recorded area 4 neuron $(1-2 \mathrm{~mm}$ apart) produced smaller-amplitude hyperpolarizations in the TC cell, leading to only one rebound spike burst at the end of the pulse train. Cortical stimuli triggered shorter-latency responses in the cortical neuron; however, the difference between the response to the first stimulus and the responses to subsequent stimuli in the pulse train was less dramatic than in the case of thalamic stimulation.

\section{Differences between various types of cortical neurons} during thalamically evoked augmenting responses

Dual simultaneous recordings from cortical neurons $(n=27)$ were performed to assess the specificity of augmentation in different areas as a function of the stimulated thalamic nucleus and to detect possible differences between superficially (above 0.8 $\mathrm{mm}$ ) and deeply (below $0.8 \mathrm{~mm}$ ) located pyramidal cells (see Fig. 12). Most dual cortical recordings were performed in precruciate area 4 and suprasylvian areas 5-7, where the boundary between the lower part of layer III (area 4) or layer IV (areas 5-7) and the

of spikes of thalamocortical cell (the line is linear fitting) in responses evoked by five VL stimuli at $10 \mathrm{~Hz}$. Right plot, Area of secondary depolarization of cortical cell as a function of the number of stimuli in the pulse trains (the line represents the mean). In a sample of 92 cells, the maximum number of fast spikes of thalamocortical cells triggered by the low-threshold spike occurred at the third to fifth stimuli. After having reached the maximum, the number of spikes in thalamocortical cells could decrease. The area of secondary depolarization of cortical cell also reached levels close to saturation at the third to fifth stimuli; however, the decrease of the depolarizing area in cortical cells was only exceptionally observed. This suggests that high levels of cortical excitability may be maintained by intracortical mechanisms. 


\section{Sponta neous}
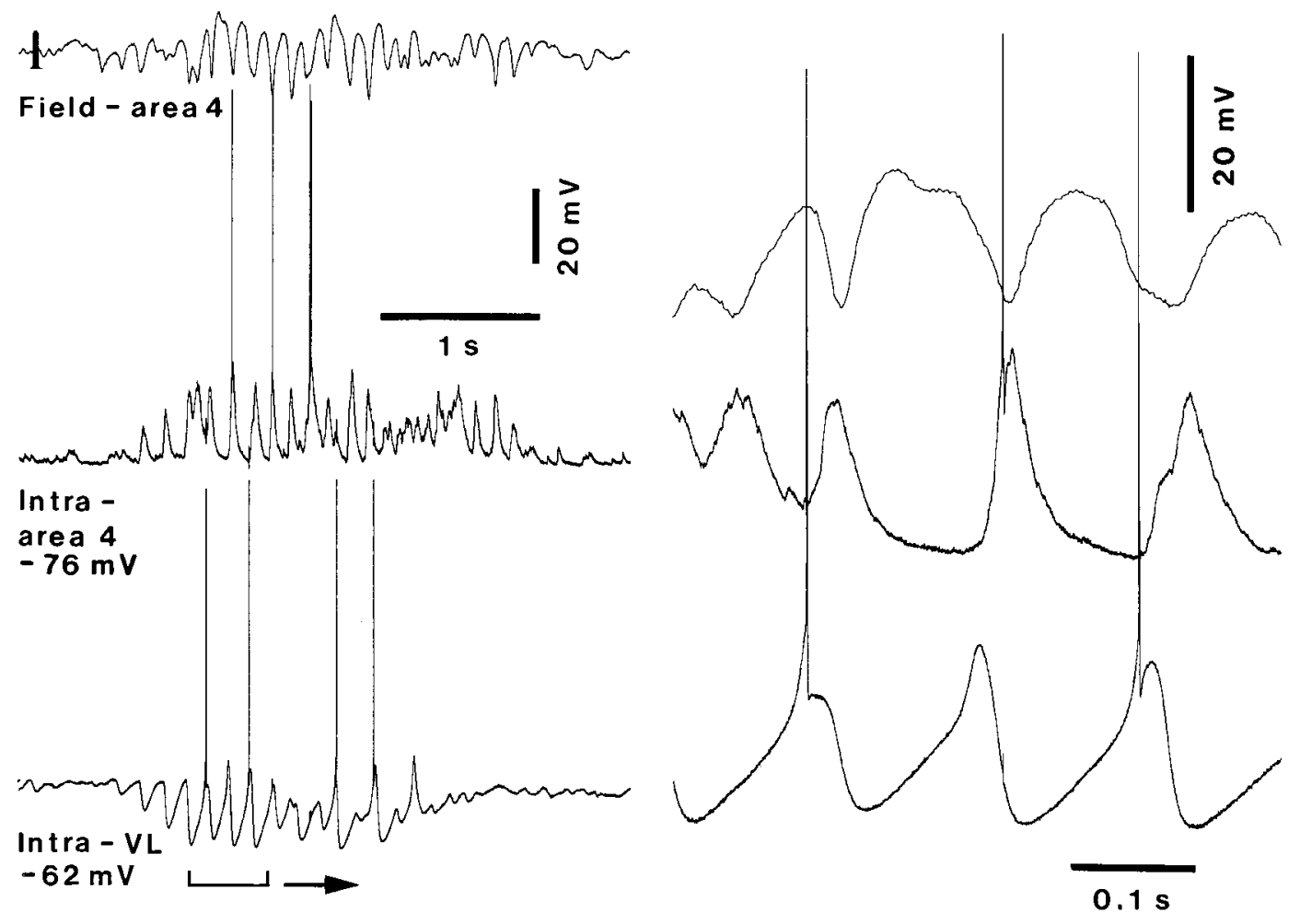

\section{Evoked}
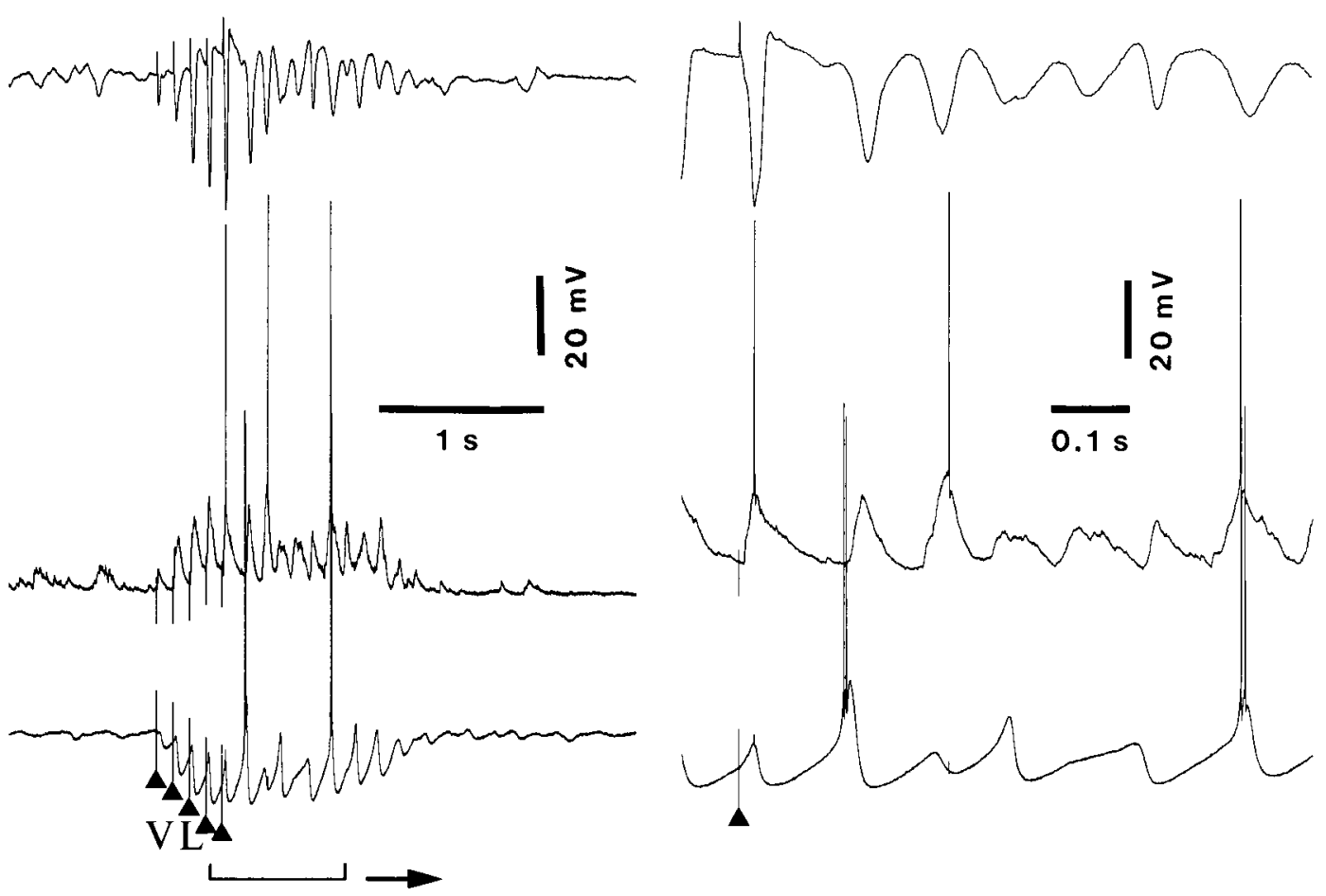

Figure 8. Spontaneously occurring spindle oscillation and thalamically evoked augmenting responses in dual intracellular recordings from VL thalamus and area 4. Barbiturate anesthesia. Parts marked by horizontal lines are expanded at right (arrows). Note LT rebound spikes in TC cell preceding the spindle-related depolarization in cortical cell, during both spontaneous and postaugmenting spindles. 


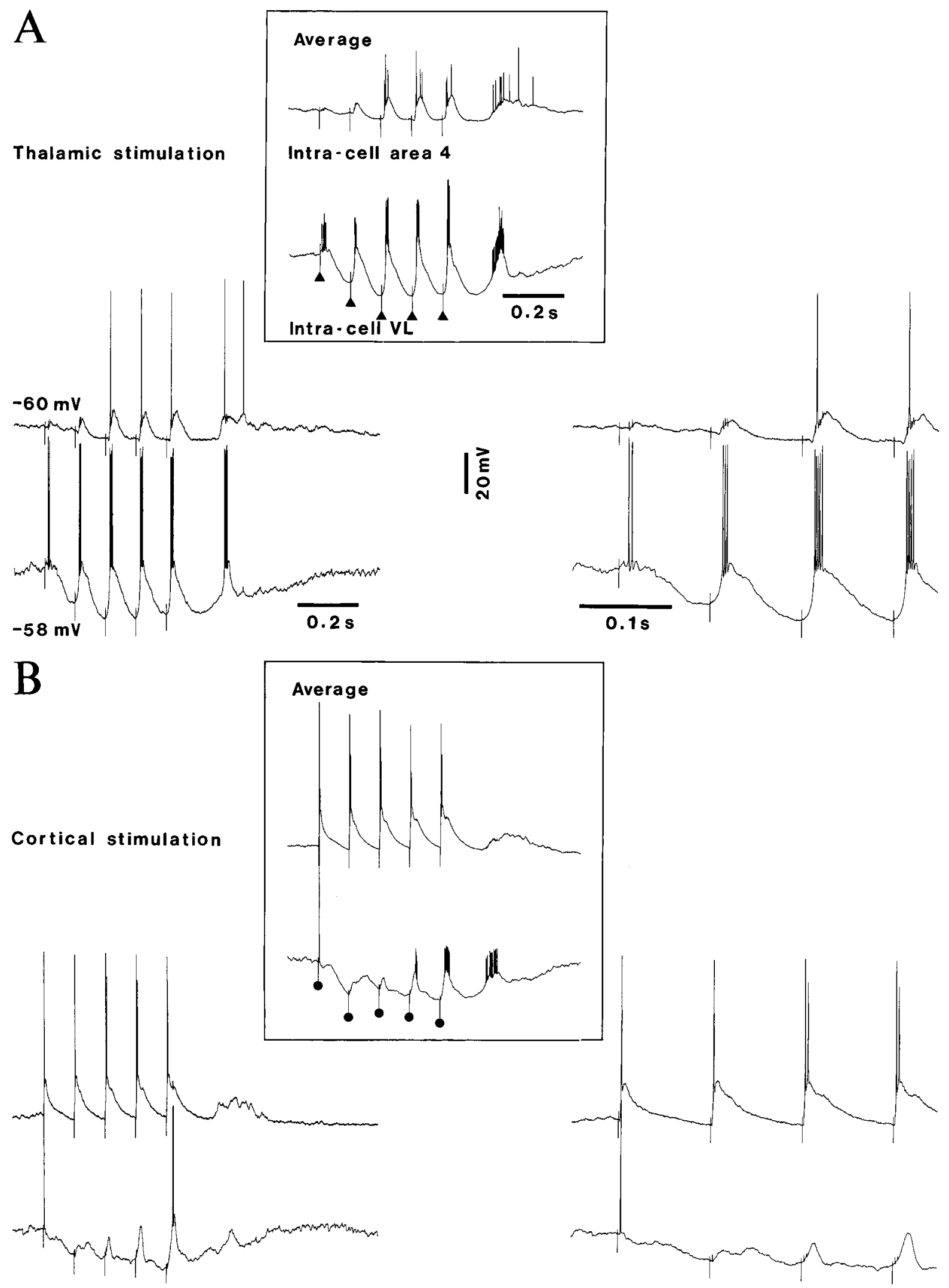

Figure 9. Differences between thalamically and cortically evoked augmenting responses in dual simultaneous recordings of thalamic (VL) and cortical (area 4) neurons. Ketamine-xylazine anesthesia. A, VL-evoked augmenting responses. At right, expanded responses to first four stimuli. Inset, Averaged responses $(n=5)$. $B$, Same neurons, but stimuli applied to area 4. 

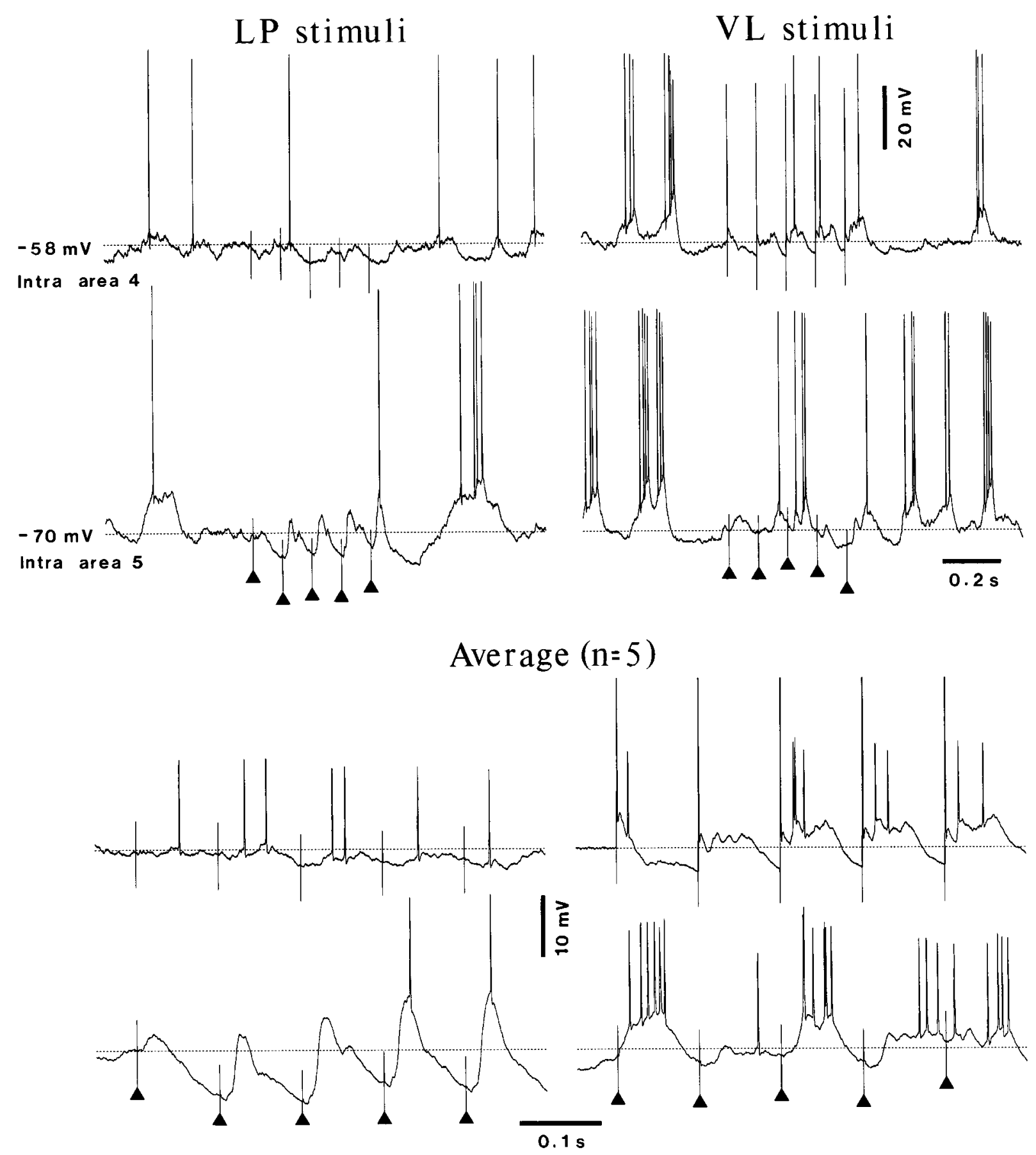

Figure 10. Specificity of augmenting responses in different thalamocortical systems: LP-evoked augmenting in area 5 and VL-evoked augmenting in area 4. Dual intracellular recordings from neurons in areas 5 (regular-spiking) and 4 (intrinsically bursting). Ketamine-xylazine anesthesia. Note that LP-evoked augmenting in area 5 developed as LT-type responses during hyperpolarization, similarly to LT augmentation in TC cells (see Discussion).

upper part of layer $\mathrm{V}$ is at $\sim 0.8 \mathrm{~mm}$ below the surface of the cortex [Hassler and Muhs-Clement (1964), their Figs. 13, 19, 30, 31].

Simultaneous intracellular recordings from cortical areas 5 and 4 (Fig. 10) revealed that augmenting responses were largely restricted to area 5 when stimulating the thalamic LP nucleus (which projects heavily to that suprasylvian area), whereas the area 4 neuron showed negligible, if any, augmentation. The area 5 neuron displayed a depolarizing response of increased amplitude during the hyperpolarization elicited by thalamic LP stimulation. This aspect is not usually observed in other cortical neurons, which generally showed augmenting responses over a depolarizing envelope (Figs. 3-8; also see the sustained hyperpolarization in Fig. 5, similar to that in Fig. 10). In the case of LP-evoked responses in area 5 neuron, the LT response deinactivated by membrane hyperpolarization was preceded by a small depolarizing response, probably an EPSP of thalamic origin (Fig. 10 , bottom panel with averaged responses). The VL stimulation elicited augmentation in the intrinsically bursting cell recorded from area 4, in contrast with no sign of augmentation observed in area 5 (see averaged responses). 

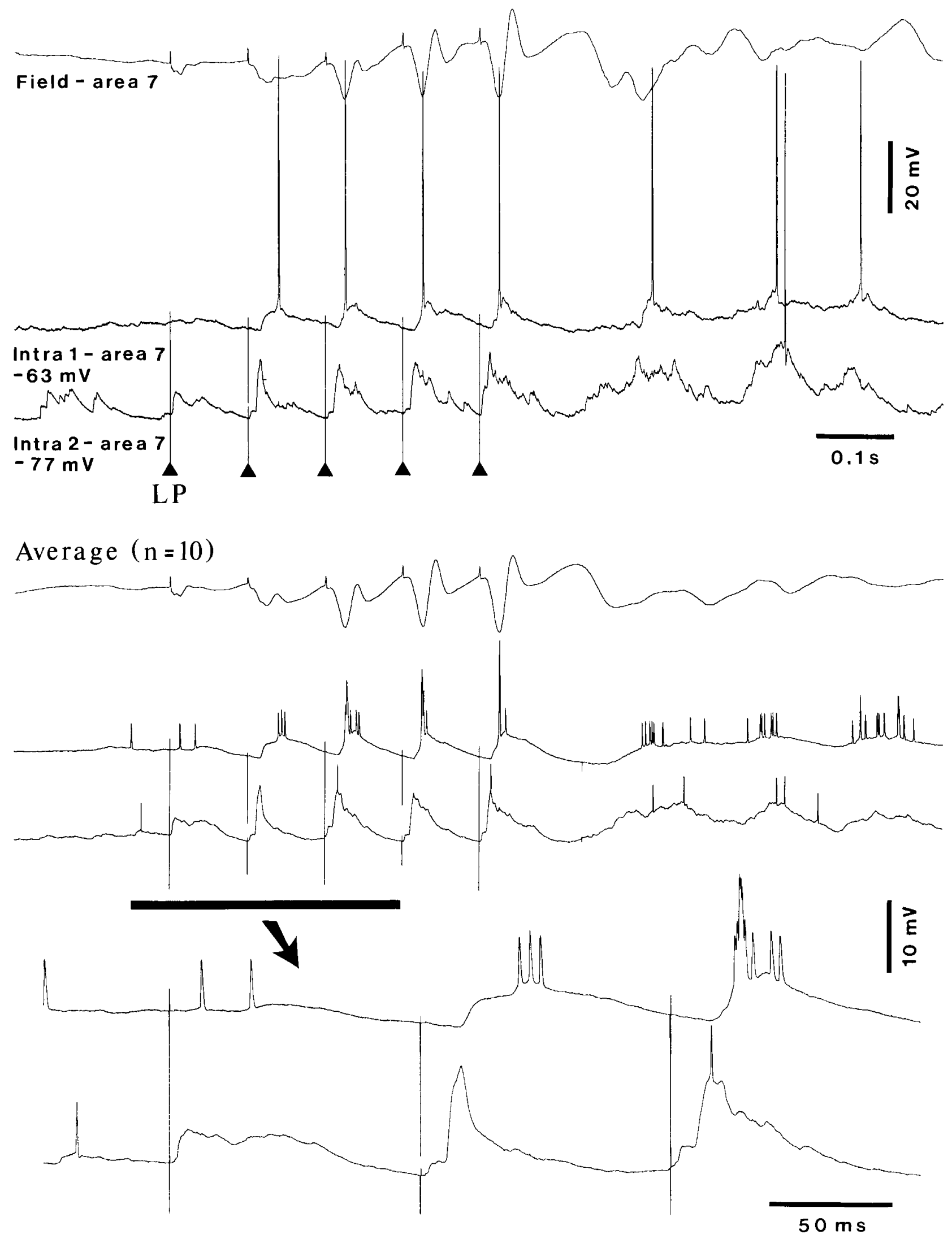

Figure 11. Comparison between LP-evoked responses in two, simultaneously recorded, neurons from area 7: Intra 1 at a depth of 0.65 mm and Intra 2 at $0.9 \mathrm{~mm}$ (see morphological features of these intracellularly stained pyramidal neurons in Fig. 12). The average of 10 responses is shown below at two time scales to compare the latencies of excitatory responses. Note shorter latency of the secondary depolarization, characterizing augmenting responses, in the deeply lying pyramidal cell. 


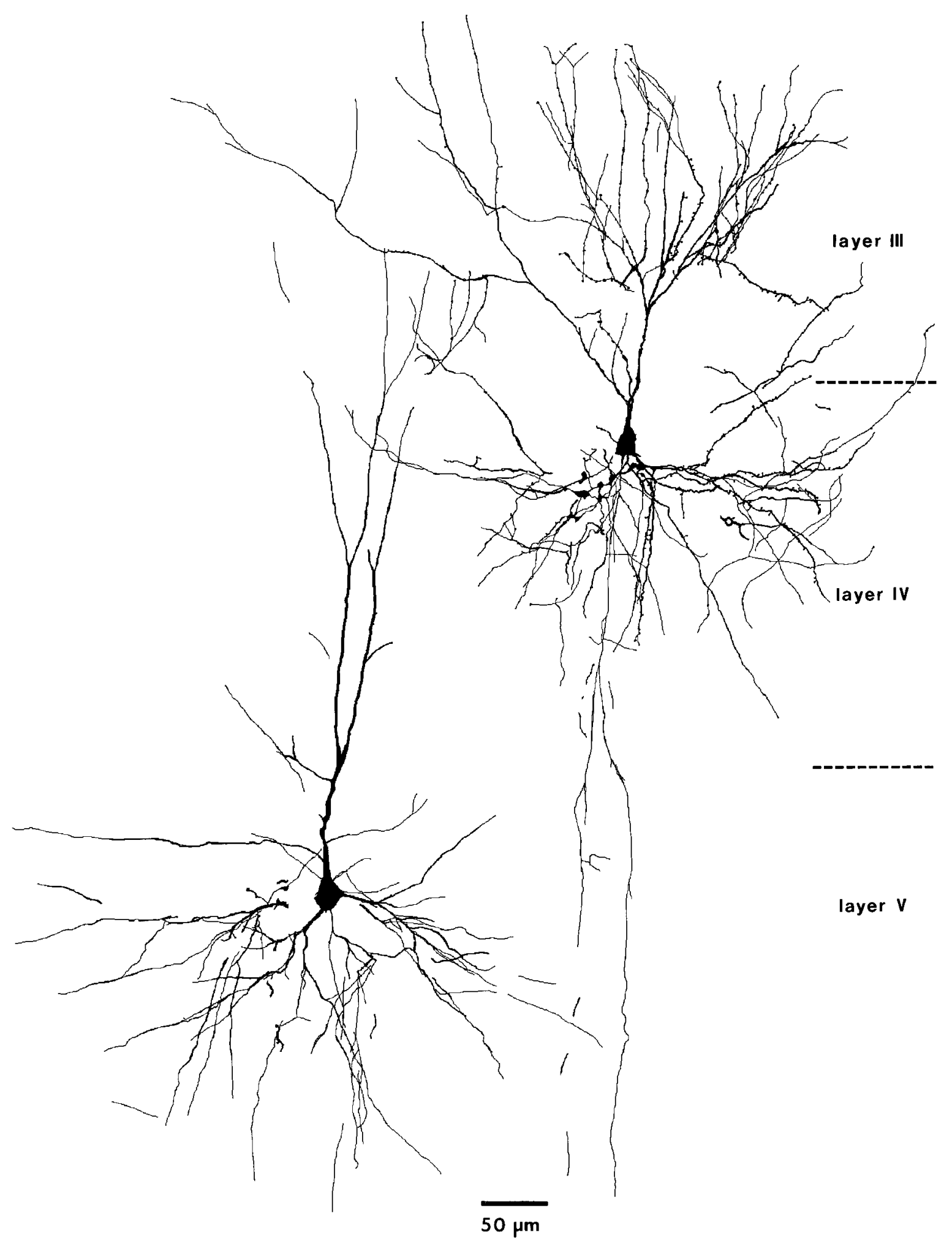

Figure 12. Two intracellularly stained pyramidal cells whose thalamically evoked augmenting responses are depicted in Figure 11 . Intra 1 was located in the upper part of layer IV and Intra 2 was located in layer V. Boundaries between layers III, IV, and V are tentatively indicated from Nissl-stained sections of area 7 [Hassler and Muhs-Clement (1964), their Fig. 31].

We analyzed the degree of augmentation in cortical neurons that were simultaneously recorded from superficial (above 0.8 $\mathrm{mm}$ ) and deep (below $0.8 \mathrm{~mm}$ ) layers. The typical example shown in Figure 11 illustrates two adjacent pyramidal neurons from area
7 that were stained (Fig. 12) and found to be located at depths of $0.65 \mathrm{~mm}$ (Fig. 11, Intra 1) and $0.9 \mathrm{~mm}$ (Fig. 11, Intra 2), respectively. Although both neurons displayed augmenting responses to stimulation of the thalamic LP nucleus, the secondary depolariz- 
ing responses had a shorter latency in the deeply lying cell $(\sim 10$ msec), compared with the latency of the same component (16-18 $\mathrm{msec}$ ) in the more superficial neuron. Precursor activity in the deeply lying cell was also observed in the self-sustained, postaugmenting rhythmic waves.

Finally, we compared the augmenting responses in a sample of regular-spiking cells $(n=5)$ and fast rhythmic-bursting cells $(n=$ 5) from superficial layers II-IV and deep layers V-VI. Fast rhythmic-bursting cells were identified by responses to depolarizing current pulses (for details, see Steriade et al., 1998). Figure 13 illustrates superimpositions of thalamically evoked augmenting responses in two neurons of each type, recorded more superficially than $0.8 \mathrm{~mm}$ and deeper than $0.8 \mathrm{~mm}$. Deeply lying regularspiking as well as fast rhythmic-bursting neurons displayed stronger augmenting responses, with shorter latencies, than more superficially located neurons.

\section{DISCUSSION}

We report four major findings: (1) thalamically evoked augmenting responses of cortical neurons mainly result from the selective enhancement of a secondary depolarization, whereas the early excitation is simultaneously reduced in a majority $(>75 \%)$ of tested neurons; (2) deeply lying (below $0.8 \mathrm{~mm}$ ) regular-spiking and fast rhythmic-bursting neurons display a greater propensity and shorter latency for augmenting responses than neurons of both categories located more superficially; (3) the augmented secondary depolarization of cortical neurons is preceded by LTtype rebound spike bursts in simultaneously recorded TC cells; and (4) postaugmenting, self-sustained oscillations, within the same frequency range as responses to pulse trains $(10 \mathrm{~Hz})$ applied to thalamic nuclei, persist for longer periods in cortical than in TC cells.

\section{Multiple mechanisms underlying cortical augmenting responses}

In the majority of cortical neurons, thalamically elicited augmentation resulted from a selective increase of the secondary depolarization associated with a reduction in the early EPSP (Figs. 2, 3 ). This aspect is the intracellular counterpart of earlier local field potential data and extracellular unit recordings from somatosensory [Steriade and Morin, (1981), their Fig. 6] and suprasylvian association [Steriade, (1991), his Fig. 4] cortices. In those studies, the probability of single action potentials and, relatedly, the amplitude of the early depth negativity of field potentials evoked by appropriate thalamic stimuli were reduced or abolished at the second stimulus at $10 \mathrm{~Hz}$, whereas the secondary depth negativity was simultaneously enhanced and accompanied by spike trains at high frequencies. The diminution in amplitude and associated discharges related to the early cortical EPSP during thalamically evoked augmenting responses may be ascribed to two, nonexclusive mechanisms: (1) a decrease in input resistance of cortical neurons as a result of the action of local GABAergic neurons (I. Timofeev and M. Steriade, unpublished data; also see below); and (2) the IPSPs in TC cells may prevent the triggering of monosynaptically elicited action potentials in many cortically projecting cells. The increase in the cortical secondary depolarization could contribute, in addition to the intrathalamic mechanisms (Steriade and Timofeev, 1997; Timofeev and Steriade, 1998), to the appearance of a secondary depolarization in related TC neurons [Steriade and Deschênes, (1984), their Fig. 13].

It has been suggested (Purpura et al., 1964; Creutzfeldt et al., 1966) that the increased secondary depolarization in cortical neurons results from the attenuation of hyperpolarizing potentials during repetitive stimulation. Typical augmenting responses occur, however, in cortical neurons even when hyperpolarization cannot be detected in response to the first and subsequent stimuli as well as when hyperpolarizing potentials are not diminished or may even increase (Figs. 5, 10, 11). Thus, factors other than the reduction in hyperpolarization may account for the increased secondary depolarization of augmented responses evoked by thalamic stimulation. There are at least three such factors: augmenting-related postinhibitory spike bursts in TC cells, intrinsic membrane properties of cortical neurons that are uncovered by hyperpolarization, and particular types of cortical neurons that exhibit a high propensity for rhythmic, high-frequency spike bursts. These factors are discussed below.

(1) The present data demonstrate that in all simultaneously recorded TC and cortical neurons $(n=32)$ the first action potential in the LT rebound bursts of TC cells precedes by short latencies $(\sim 3 \mathrm{msec})$ the augmented depolarization in cortical neurons. This result points to thalamic incremental responses as a major source for cortical augmentation. We considered here only the LT-type augmenting responses that are deinactivated by membrane hyperpolarization. The temporal relation between the other (HT) type of augmenting potentials in TC cells (Steriade and Timofeev, 1997) and target cortical cells remains to be investigated. The proportion of TC neurons generating HT-type augmenting responses in animals with intact thalamocorticothalamic loops is much smaller $(\sim 10 \%)$ than in decorticated animals (Steriade and Timofeev, 1997). This is probably attributable to the fact that the corticothalamic feedback drives GABAergic RE neurons, with obvious inhibitory influences on TC cells and prevalent appearance of LT-type augmenting responses. The role of TC-cell LT rebound bursts in priming augmenting cortical responses is also suggested by the facilitation of cortical augmentation when preceded by spontaneous spindles (Fig. 4). Compared with control epochs, the spindles are associated with powerful IPSPs in TC cells, followed by rebound spike bursts that are transferred to cortex, where they produce the enhancement of the secondary depolarization, typical for augmentation.

(2) In view of incremental responses arising from a hyperpolarized membrane in cortical cells (Figs. 5, 10, 11), we propose that another factor promoting augmentation is the activation of inhibitory cortical neurons driven by thalamic repetitive stimuli. Abundant evidence shows that TC axons contact the different varieties of local circuit inhibitory interneurons (Jones, 1975, 1981). During sleep spindles, the naturally occurring phenomenon mimicked by augmenting responses, the rhythmic volleys from TC cells produce powerful inhibitory effects on cortical pyramidal cells, as revealed by the transformation of reversed IPSPs, with $\mathrm{Cl}^{-}$-filled pipettes, into robust bursts resembling paroxysmal depolarizing shifts during seizures (Contreras et al., 1997a). Thus, the strength of thalamic inputs during spindles, leading to bisynaptic inhibition of pyramidal cells, is more effective than expected solely based on reduced discharge frequencies of pyramidal tract neurons during resting sleep (Evarts, 1964; Steriade et al., 1974). Thalamically induced hyperpolarization of cortical neurons is not exclusively attributable to GABAergic inhibition. Indeed, under in vivo conditions, with significant spontaneous neuronal activity, the $\mathrm{GABA}_{\mathrm{A}}$-mediated monophasic IPSP in neocortical neurons (Pollen and Lux, 1966; Contreras et al., 1997b) shuts off discharges in a large proportion of cells, thus contributing to a disfacilitation phenomenon during which $\mathrm{K}^{+}$ currents dominate the membrane behavior (Contreras et al., 

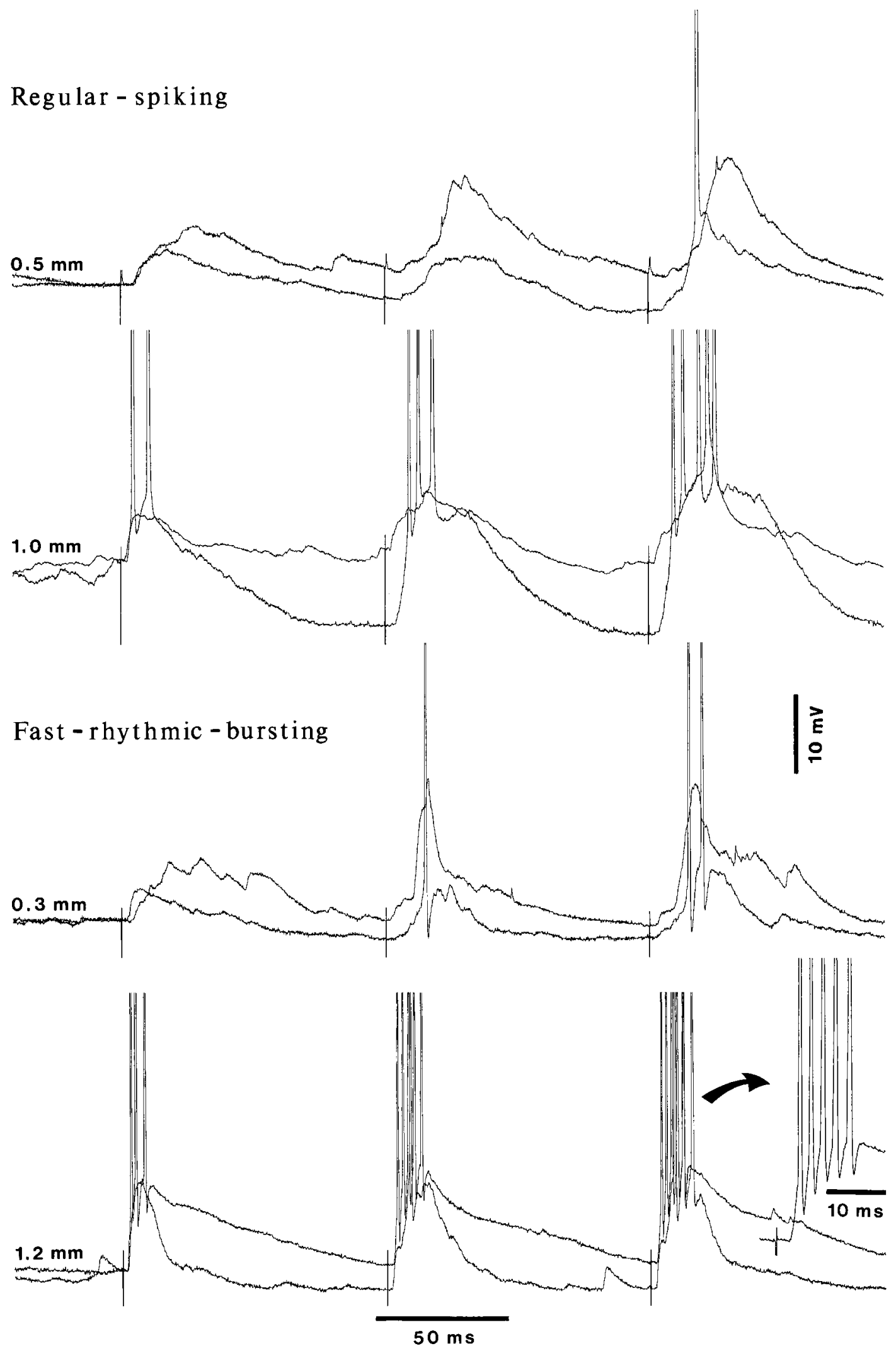

Figure 13. Superimposed responses of superficial (above $0.8 \mathrm{~mm}$ ) and deep (below $0.8 \mathrm{~mm}$ ) regular-spiking and fast rhythmic-bursting cells during augmenting responses elicited by thalamic stimulation. In each case, responses from two different cells of each type are superimposed. The high-frequency burst of a fast rhythmic-bursting cell at a depth of $1.2 \mathrm{~mm}$ is expanded at right (arrow). 
1996). All these factors, leading to prolonged hyperpolarizations in cortical neurons, are likely to deinactivate LT currents and to generate, through rebound spike bursts, augmenting responses. $\mathrm{Ca}^{2+}$-dependent $\mathrm{LT}$ responses, at the break of a hyperpolarizing current pulse, have been described in morphologically identified pyramidal and nonpyramidal cells from slices of rat and guinea pig frontal cortex (Kawaguchi, 1993; de la Peña and GeijoBarrientos, 1996). Neurons displaying such responses were found in layers V-VI and were absent in more superficial layers (de la Peña and Geijo-Barrientos, 1996) as found in the present experiments (Figs. 10, 11). The role of inhibitory interneurons during augmenting responses is elaborated in the companion modeling study (Bazhenov et al., 1998b).

(3) Deeply lying fast rhythmic-bursting cells displaying highfrequency spike bursts (Steriade et al., 1998) probably have a greater impact than regular-spiking cells, discharging single action potentials, on many neurons in the same or adjacent columns during responses to successive stimuli in pulse trains at $10 \mathrm{~Hz}$ (Fig. 13). The stronger augmenting responses in deep cortical layers corroborate the data on other types of layer $\mathrm{V}$ cells, reported by Castro-Alamancos and Connors (1996b).

\section{Roles played by the thalamus and neocortex in augmenting responses}

Thalamic repetitive stimulation produces stronger augmenting responses in cortical neurons than does cortical stimulation (Fig. 9) because of intrathalamic incremental responses (Steriade and Timofeev, 1997) consisting of repetitive spike bursts that are transferred from TC to target cortical neurons. The inclusion of the thalamus in this circuit explains the differences between cortical augmenting responses in the presence of the thalamus and those recorded in somatosensory cortex after destruction of the corresponding thalamic nuclei (Morin and Steriade, 1981). A decrease in the inhibitory phase after the first thalamic stimulus in a pulse train at $10 \mathrm{~Hz}$ can be produced by brainstem reticular activation. Under these experimental conditions, the postinhibitory rebound is produced before the second stimulus is delivered, and the augmenting responses to the second as well as following stimuli are decreased in amplitude or abolished [Steriade and Morin (1981), their Fig. 5]. This result emphasizes the role of postinhibitory rebound bursts in TC cells in the production of cortical augmentation. However, the fact that augmentation also occurs in thalamically lesioned animals and that the shortened latency of rebound bursts similarly leads to diminished augmenting responses together indicate that inhibitory processes in the cerebral cortex also contribute to augmentation (Steriade and Morin, 1981). This conclusion is congruent with recent intracellular data (Castro-Alamancos and Connors, 1996b) and modeling studies (Bazhenov et al., 1998b).

The possible contribution of intracortical circuits to the production of augmenting responses is further strengthened by the presence of self-sustained, postaugmenting oscillatory responses that are longer-lasting in cortex than in related thalamic foci (Fig. 7). This was also apparent in dual intracellular recordings, in which the duration of spontaneously occurring spindle sequences in TC cells was shorter than in cortical cells (Fig. 8). In agreement with field potential studies in rat neocortex (Kandel and Buzsáki, 1997), these observations suggest that complex intracortical circuits have a major influence on the incoming thalamocortical inputs and can amplify oscillatory activity arising in the thalamus. Moreover, cortical responses could lead to the spread of oscillatory activity to remote cortical foci by corticothalamocortical loops (Bazhenov et al., 1998b) that return to areas outside those where the original pathways originate (Kato, 1990). The selfsustained oscillatory activity that follows augmenting responses may lead to paroxysmal activity that is largely generated intracortically. This is a form of cortical short-term plasticity, because the repetition of cortical pulse trains at $10 \mathrm{~Hz}$ led in deeply lying intrinsically bursting cells, recorded from the homotopic cortical area in the contralateral hemisphere of athalamic animals, to (1) a progressive depolarization of cortical neurons, (2) an increase in the depolarization area of synaptically evoked responses, (3) an increased number of action potentials to testing stimuli, and (4) self-sustained seizures [Steriade et al. (1993b), their Fig. 14]. The role of intrinsically bursting layer $\mathrm{V}$ cells in augmenting responses was also emphasized by Castro-Alamancos and Connors (1996b). The fast rhythmic-bursting cortical neurons recorded from layers V-VI, some of them with identified thalamic projections (Steriade et al., 1998), represent another strong candidate for such processes (Fig. 13). The role of corticothalamic neurons in rhythmic oscillations was also emphasized by Kao and Coulter (1997).

Thalamocortical augmenting responses are modulated by behavioral states of vigilance in naturally sleeping and aroused cats (Steriade et al., 1969) and rats (Castro-Alamancos and Connors, 1996c); they are maximal during epochs in which the animals are still and when they display spontaneous spindle oscillations within the frequency range of evoked responses, whereas they are suppressed during strong arousal. These data, together with the previously mentioned results on the development from augmenting responses to seizures, are consistent with the preferential occurrence of some types of paroxysmal activities during drowsiness and light sleep (Steriade, 1974).

\section{Concluding remarks}

Augmenting responses, whose study is relevant for short-term plasticity processes in both normal and pathological states, can be generated in either the thalamus in the absence of the cortex or the cerebral cortex of athalamic animals. However, the preservation of reciprocal corticothalamic circuits in intact-brain preparations ensures, first, the production of postinhibitory rebound spike bursts in TC cells that are transferred to cortex and are followed by secondary depolarizations, which are typical for augmenting responses in cortical cells, and, second, the amplification of thalamof ugal volleys by intracortical excitatory and disinhibitory circuits.

\section{REFERENCES}

Bazhenov M, Timofeev I, Steriade M, Sejnowski TJ (1998a) Cellular and networks models for intrathalamic augmenting responses during 10 Hz stimulation. J Neurophysiol 79:2730-2748.

Bazhenov M, Timofeev I, Steriade M, Sejnowski TJ, (1998b) The computer models for thalamocortical augmenting responses. J Neurosci 18:6444-6465.

Castro-Alamancos M, Connors BW (1996a) Spatiotemporal properties of short-term plasticity in sensorimotor thalamocortical pathways of the rat. J Neurosci 16:2767-2779.

Castro-Alamancos M, Connors BW (1996b) Cellular mechanisms of the augmenting response: short-term plasticity in a thalamocortical pathway. J Neurosci 16:7742-7756.

Castro-Alamancos M, Connors BW (1996c) Short-term plasticity of a thalamocortical pathway dynamically modulated by behavioral state. Science 272:274-277.

Connors BW, Gutnick MJ, Prince DA (1982) Electrophysiological properties of neocortical neurons in vitro. J Neurophysiol 48:1302-1320.

Contreras D, Steriade M (1995) Cellular basis of EEG slow rhythms: a study of dynamic corticothalamic relationships. J Neurosci 15:604-622.

Contreras D, Timofeev I, Steriade M (1996) Mechanisms of long-lasting 
hyperpolarizations underlying slow sleep oscillation in cat corticothalamic networks. J Physiol (Lond) 494:251-264.

Contreras D, Destexhe A, Steriade M (1997a) Intracellular and computational characterization of the intracortical inhibitory control of synchronized thalamic inputs in vivo. J Neurophysiol 78:335-350.

Contreras D, Dürmüller N, Steriade M (1997b) Absence of a prevalent laminar distribution of IPSPs in association cortical neurons of cat. J Neurophysiol 78:2742-2753.

Creutzfeldt OD, Watanabe S, Lux HD (1966) Relations between EEG phenomena and potentials of single cortical cells. I. Evoked responses after thalamic and epicortical stimulation. Electroencephalogr Clin Neurophysiol 20:1-18.

Crunelli V, Haby M, Jassik-Gerschenfeld D, Leresche N, Pirchio M (1988) $\mathrm{Cl}^{-}$- and $\mathrm{K}^{+}$-dependent inhibitory postsynaptic potentials evoked by interneurones of the rat lateral geniculate nucleus. J Physiol (Lond) 399:153-176.

de la Peña E, Geijo-Barrientos E (1996) Laminar localization, morphology, and physiological properties of pyramidal neurons that have lowthreshold calcium current in the guinea-pig medial frontal cortex. J Neurosci 16:5301-5311.

Deschênes M, Paradis M, Roy JP, Steriade M (1984) Electrophysiology of neurons of lateral thalamic nuclei in cat: resting properties and bursting discharges. J Neurophysiol 51:1196-1219.

Domich L, Oakson G, Steriade M (1986) Thalamic burst patterns in the naturally sleeping cat: a comparison between cortically-projecting and reticularis neurones. J Physiol (Lond) 379:429-450.

Evarts EV (1964) Temporal patterns of discharge of pyramidal tract neurons during sleep and waking in the monkey. J Neurophysiol 27:152-171.

Ferster D, Lindström S (1985) Augmenting responses evoked in area 17 of the cat by intracortical axonal collaterals of cortico-geniculate cells. J Physiol (Lond) 367:217-232.

Glenn LL, Hada J, Roy JP, Deschênes M, Steriade M (1982) Anterograde tracer and field potential analysis of the neocortical layer I projection from nucleus ventralis medialis of the thalamus in cat. Neuroscience 7:1861-1877.

Gray CM, McCormick DA (1996) Chattering cells: superficial pyramidal neurons contributing to the generation of synchronous oscillations in the visual cortex. Science 274:109-113.

Hassler R, Muhs-Clement K (1964) Architektonischer Aufbau des sensorimotorischen und parietalen Cortex der Katze. J Hirnforsch 6:377-420.

Hirsch JC, Burnod Y (1987) A synaptically evoked late hyperpolarization in the rat dorso-lateral geniculate nucleus in vitro. Neuroscience 23:457-468.

Jahnsen H, Llinás R (1984) Electrophysiological properties of guineapig thalamic neurones: an in vitro study. J Physiol (Lond) 349:205-226.

Jones EG (1975) Varieties and distribution of non-pyramidal cells in the somatic sensory cortex of the squirrel monkey. J Comp Neurol 160:205-268.

Jones EG (1981) Anatomy of cerebral cortex: columnar input-output organization. In: The organization of the cerebral cortex (Schmitt FO, Worden G, Adelman G, Dennis SG, eds), pp 199-235. Cambridge, MA: MIT.

Jones EG (1985) The thalamus. New York: Plenum.

Kandel A, Buzsáki G (1997) Cellular-synaptic generation of sleep spindles, spike-and-wave discharges, and evoked thalamocortical responses in the neocortex of rat. J Neurosci 17:6783-6797.

Kao CQ, Coulter DA (1997) Physiology and pharmacology of corticothalamic stimulation-evoked responses in rat somatosensory thalamic neurons in vitro. J Neurophysiol 77:2661-2676.

Kato N (1990) Cortico-thalamo-cortical projection between visual cortices. Brain Res 509:150-152.

Kawaguchi Y (1993) Groupings of nonpyramidal and pyramidal cells with specific physiological and morphological characteristics in rat frontal cortex. J Neurophysiol 69:416-431.

McCormick DA, Connors BW, Lighthall JW, Prince DA (1985) Comparative electrophysiology of pyramidal and sparsely spiny stellate neurons of the neocortex. J Neurophysiol 54:782-806.

Morin D, Steriade M (1981) Development from primary to augmenting responses in the somatosensory system. Brain Res 205:49-66.
Morison RS, Bassett DL (1945) Electrical activity of the thalamus and basal ganglia in decorticate cats. J Neurophysiol 8:309-314.

Morison RS, Dempsey EW (1942) A study of thalamocortical relations. Am J Physiol 135:281-292.

Morison RS, Dempsey EW (1943) Mechanism of thalamocortical augmentation and repetition. Am J Physiol 138:297-308.

Nuñez A, Amzica F, Steriade M (1993) Electrophysiology of cat association cortical cells in vivo: intrinsic properties and synaptic responses. J Neurophysiol 70:418-430.

Paré D, Curró Dossi R, Steriade M (1991) Three types of inhibitory postsynaptic potentials generated by interneurons in the anterior thalamic complex of cat. J Neurophysiol 66:1190-1204.

Pollen D, Lux H (1966) Conductance changes during inhibitory postsynaptic potentials in normal and strychninized cortical neurons. J Neurophysiol 29:367-381.

Purpura DP, Shofer RJ, Musgrave FS (1964) Cortical intracellular potentials during augmenting and recruiting responses. II. Patterns of synaptic activities in pyramidal and non-pyramidal tract neurons. J Neurophysiol 27:133-151.

Spencer WA, Brookhart JM (1961) Electrical patterns of augmenting and recruiting waves in depths of sensorimotor cortex of cat. J Neurophysiol 24:26-49.

Steriade M (1974) Interneuronal epileptic discharges related to spikeand-wave cortical seizures in behaving monkeys. Electroencephalogr Clin Neurophysiol 37:247-263.

Steriade M (1991) Alertness, quiet sleep, dreaming. In: Cerebral cortex, Vol 9, Normal and altered states of function (Peters A, Jones EG, eds), pp 279-357. New York: Plenum.

Steriade M (1997) Synchronized activities of coupled oscillators in the cerebral cortex and thalamus at different levels of vigilance. Cereb Cortex 7:583-604.

Steriade M, Deschênes M (1984) The thalamus as a neuronal oscillator. Brain Res Rev 8:1-63.

Steriade M, Morin D (1981) Reticular influences on primary and augmenting responses in the somatosensory cortex. Brain Res 205:67-80.

Steriade M, Timofeev I (1997) Short-term plasticity during intrathalamic augmenting responses in decorticated cats. J Neurosci 17:3778-3795.

Steriade M, Iosif G, Apostol V (1969) Responsiveness of thalamic and cortical motor relays during arousal and various stages of sleep. J Neurophysiol 32:251-265.

Steriade M, Deschênes M, Oakson G (1974) Inhibitory processes and interneuronal apparatus in motor cortex during sleep and waking. I. Background firing and responsiveness of pyramidal tract neurons and interneurons. J Neurophysiol 37:1065-1092.

Steriade M, Domich L, Oakson G (1986) Reticularis thalami neurons revisited: activity changes during shifts in states of vigilance. J Neurosci 6:68-81.

Steriade M, Domich L, Oakson G, Deschênes M (1987) The deafferented reticular thalamic nucleus generates spindle rhythmicity. J Neurophysiol 57:260-273.

Steriade M, Nuñez A, Amzica F (1993a) A novel (<1 Hz) oscillation of neocortical neurons in vivo: depolarizing and hyperpolarizing components. J Neurosci 13:3252-3265.

Steriade M, Nuñez A, Amzica F (1993b) Intracellular analysis of relations between the slow $(<1 \mathrm{~Hz})$ oscillation and other sleep rhythms of the electroencephalogram. J Neurosci 13:3266-3283.

Steriade M, Jones EG, McCormick DA (1997) Thalamus, Vol 1, Organisation and function. Oxford: Elsevier.

Steriade M, Timofeev I, Dürmüller N, Grenier F (1998) Dynamic properties of corticothalamic neurons and local cortical interneurons generating fast rhythmic $(30-40 \mathrm{~Hz})$ spike bursts. J Neurophysiol 79:483-490.

Timofeev I, Steriade M (1997) Fast (mainly 30-100 Hz) oscillations in the cat cerebellothalamic pathway and their synchronization with cortical potentials. J Physiol (Lond) 504:153-168.

Timofeev I, Steriade M (1998) Intrathalamic mechanisms underlying incremental responses in reticular and relay neurons. J Neurophysiol 79:2716-2729. 